1 Short title: Magnesium regulates circadian period in Arabidopsis

2

3 Author to whom correspondence should be sent:

$4 \quad$ Nathalie Verbruggen

5 Laboratory of Plant Physiology and Molecular Genetics

6 Université libre de Bruxelles,

71050 Brussels, Belgium

$8 \quad$ E mail: nverbru@ulb.ac.be 


\section{Magnesium maintains length of circadian period in Arabidopsis thaliana}

11 J. Romário F. de Melo ${ }^{1, \$}$, Annelie Gutsch ${ }^{1,2, \$}$, Joëlle De Caluwé ${ }^{3}$, Jean-Christophe Leloup ${ }^{3}$,

12 Didier Gonze ${ }^{3}$, Christian Hermans ${ }^{4}$, Alex A.R. Webb ${ }^{2}$, Nathalie Verbruggen ${ }^{{ }^{*}}$

14 Author Affiliation:

$15{ }^{1}$ Laboratory of Plant Physiology and Molecular Genetics, Université libre de Bruxelles, 1050

16 Brussels, Belgium

$17{ }^{2}$ Department of Plant Sciences, University of Cambridge, CB2 3EA Cambridge, UK

$18{ }^{3}$ Unité de Chronobiologie Théorique, Université libre de Bruxelles, 1050 Brussels, Belgium

$19{ }^{4}$ Crop Production and Biostimulation Laboratory, Université libre de Bruxelles, 1050 Brussels,

20 Belgium

21 \$ joint first authorship

22 * Corresponding author: Laboratory of Plant Physiology and Molecular Genetics, Université libre

23 de Bruxelles, 1050 Brussels, Belgium. E-mail: nverbru@ulb.ac.be

25 One sentence summary: Magnesium maintains the circadian period in Arabidopsis seedlings 26 and interferes with the circadian oscillator most likely through translational mechanisms. 


\section{Authors contribution}

$29 \mathrm{~J}-\mathrm{CL}, \mathrm{CH}, \mathrm{AW}$ and NV conceived the project and acquired the funding. DG, CH, NV, AW, AG 30 and JRFM designed the experiments. JRFM and AG performed the experiments and analysed 31 the data. JDC, DG and JRFM designed and analysed the modelling data. JDC carried out the 32 numerical simulations. All authors participated in data analysis discussions. JRFM and AG 33 wrote the manuscript to which all co-authors contributed.

34 Responsibilities of the Author for Contact:

35 The author responsible for the distribution of materials integral to the findings presented in this 36 article in accordance with the policy described in the Instructions for Authors 37 (www.plantphysiol.org) is: Nathalie Verbruggen (nverbru@ulb.ac.be).

38 Funding information:

39 This research was funded by Actions de Recherche Concertée (ARC 2012-2017), French 40 community of Belgium, F.R.S.-FNRS (PDR T 0085.16 2016-2020), 'Fonds Emile DEFAY and 41 Fonds d'Encouragement à la Recherche as well as Foundation Wiener-Anspach at ULB. 


\section{Abstract}

44 The circadian clock coordinates the physiological response of a biological system to day and

45 night rhythms through complex loops of transcriptional/ translational regulation. It can respond

46 to external stimuli and adjust generated circadian oscillations accordingly to keep an

47 endogenous period close to $24 \mathrm{~h}$. To date, the interaction between nutritional status and

48 circadian rhythms in plants is poorly understood. Magnesium (Mg) is essential for numerous

49 biological processes in plants and its homeostasis is crucial to maintain optimal development

50 and growth. Magnesium deficiency in young Arabidopsis thaliana seedlings increased the

51 circadian period of pCCA1:LUC oscillations and dampened its amplitude in constant light in a

52 dose-dependent manner. Although circadian period increase by $\mathrm{Mg}$ deficiency was light

53 dependent, it did not depend on active photosynthesis. Mathematical modelling of the Mg input

54 to the circadian clock reproduced the experimental increase of the circadian period and

55 suggested that $\mathrm{Mg}$ is likely to affect global transcription/translation levels rather than a single

56 component of the circadian oscillator. The model prediction was supported by a synergistic

57 interaction between $\mathrm{Mg}$ deficiency and cyclohexamide, an inhibitor of translation. These findings

58 suggest that proper $\mathrm{Mg}$ supply is required to support proper timekeeping in plants.

\section{Introduction}

60 Magnesium (Mg) is one of the most abundant elements in the Earth's crust (Clark and 61 Washington, 1924; Fleischer, 1954) and in sea water (Culkin and Cox, 1966). It plays many 62 roles in the metabolism of living organisms, such as maintaining ribosome structure (Akanuma 63 et al., 2018), being necessary for the active form of ATP (Fish et al., 1983; Wang et al., 1995) as 64 well as being a co-factor and allosteric modulator for numerous enzymes (Cowan, 1998). In 65 plants, $\mathrm{Mg}$ is vital to the photosynthetic machinery (Levitt, 1954) and $\mathrm{CO}_{2}$ assimilation (Hauer66 Jákli and Tränkner, 2019). Therefore, imbalances in plant $\mathrm{Mg}$ status are likely to cause 67 disorders from cellular to organismal levels. Despite its importance in cellular and organismal 68 metabolic processes across all kingdoms, Mg still does not garner as much attention as other 69 nutrients, such as $\mathrm{Ca}, \mathrm{N}, \mathrm{Zn}$ or Fe (Hermans et al., 2013).

70 Plants require usually between $1.5-3.5 \mathrm{mg} \mathrm{g}^{-1}$ dry weight for optimal growth (Grzebisz et al., 71 2009; Römheld et al., 2012). A Mg supply below $1-2 \mathrm{mg} \mathrm{g-1} \mathrm{leaf} \mathrm{dry} \mathrm{weight} \mathrm{marks} \mathrm{the} \mathrm{onset} \mathrm{of}$ 72 Mg deficiency (Hermans et al. 2004, Hermans and Verbruggen et al., 2005, Ding et al., 2006). 73 Impaired partitioning of soluble sugars leading to starch accumulation in source leaves are the 
74 first sign of Mg deficiency before defects of photosynthetic activity occur (Cakmak et al., 1994;

75 Hermans et al., 2005; Hermans and Verbruggen, 2005). Typical long-term symptoms of $\mathrm{Mg}$ 76 starvation in higher plants are interveinal leaf chlorosis, limited growth and altered biomass 77 allocation between plant organs (Verbruggen and Hermans, 2013; Hauer-Jákli and Tränkner, 78 2019). Transcriptomic studies in Arabidopsis. thaliana identified CATION EXCHANGER 3 $79(C A X 3)$ as a suitable molecular marker to monitor the $\mathrm{Mg}$ status because it responds to $\mathrm{Mg}$ 80 availability before the first visible signs of deficiency or excess occur (Hermans et al., 2010a; 81 Kamiya et al., 2012). Transcriptomic studies further revealed that both early, as well as long82 term Mg deficiency, altered the expression of genes involved in processes regulated by the 83 circadian oscillator (Hermans et al., 2010a; Hermans et al., 2010b)

84 Daily biological rhythms in plants are regulated by the circadian clock, which runs in a close-to 85 24-hour cycle synchronized to environmental cues such as light and temperature. The circadian 86 clock is maintained by endogenous rhythms of gene expression regulated by transcriptional87 translational feedback loops that influence growth, development, flowering time, responses to 88 biotic and abiotic stresses to promote plant fitness (Green et al., 2002; Harmer, 2009; 89 Greenham and McClung, 2015). The core components of the central oscillator in plants are the dawn-phased genes CIRCADIAN CLOCK-ASSOCIATED 1 (CCA1) and LATE ELONGATED HYPOCOTYL (LHY), the morning genes PSEUDO-RESPONSE REGULATOR 9 (PRR9), PRR7 and PRR5, the dusk-phased gene TIMING OF CAB EXPRESSION 1 (TOC1) and the eveningcomplex composed of EARLY FLOWERING 3 (ELF3), ELF4, and LUX ARRYHTHMO (LUX) (McClung, 2006; Webb et al., 2019). Altered expression of one or more of these oscillator components changes the circadian period, amplitude, phase and can lead to complete arrhythmia of the endogenous oscillator, which affects plant growth and development (Hicks et al., 1996; Dunlap, 1999; Alabadí et al., 2002; Webb, 2003). Therefore, optimal functioning of the circadian system relies on sensing and integrating internal as well as external signals in order to maintain an endogenous timekeeping mechanism capable of accurately anticipating environmental fluctuations (Dodd et al., 2005; Hotta et al., 2007; Robertson et al., 2009; Hsu and Harmer, 2014). Such external signals can be the nutritional status that cross talks with the circadian clock (Hong et al., 2013) and imbalanced nutritional homeostasis can interfere with circadian timekeeping. Experiments, which establish the effect of stimuli to change the phase of

104 the circadian oscillator at different times of day, so called phase response curve (PRC) 105 experiments, using pulses of nitrogen $(\mathrm{N})$ support the feedback of $\mathrm{N}$ status to the circadian 106 oscillator (Gutiérrez et al., 2008). Other studies demonstrated that $\mathrm{N}$ deficiency shortened 
107 circadian period in the photosynthetic dinoflagellate Gonyaulax polyedra (Sweeney and Folli, 108 1984; Haydon et al., 2015). Excess of copper affects amplitude and phase of CCA1 and LHY 109 expression (Andrés-Colás et al., 2010) while iron deficiency lengthens the circadian period 110 (Chen et al., 2013; Salomé et al., 2013). Furthermore, early or long-term Mg deficiency alters 111 the expression of Arabidopsis circadian oscillator genes suggesting a link between Mg 112 homeostasis and the circadian clock (Hermans et al., 2010a; Hermans et al., 2010b). While no 113 detailed study describes the interplay between $\mathrm{Mg}$ and circadian rhythms in plants, recent 114 findings suggest a key role for $\mathrm{Mg}$ in the timekeeping system in Ostreococcus tauri (Feeney et 115 al., 2016), a single-celled alga that shares a common ancestor with higher plants.

116 We show that Mg deficiency dose-dependently lengthens the circadian period of core oscillator 117 genes in $A$. thaliana, which is independent from fully functional photosynthesis. A comparable 118 period lengthening was reproduced with mathematical modelling when a global impact of $\mathrm{Mg}$ on 119 transcription and translation was simulated. Our findings demonstrate that endogenous rhythms 120 in plants strongly depend on nutritional status.

\section{Results}

122 External Mg concentrations dose-dependently increases period under continuous light 123 and impact circadian phase in light/dark cycles

124 Luciferase (LUC)-based reporters were used to examine circadian rhythms in $A$. thaliana 125 seedlings that were germinated and entrained under different $\mathrm{Mg}$ concentrations ranging from 5 $126 \mu \mathrm{M}$ to $1,500 \mu \mathrm{M}$ and thereafter released into continuous light (LL). Magnesium depletion 127 lengthened the circadian period of pCCA1:LUC activity by almost $5 \mathrm{~h}$ on average when 128 compared with Mg-replete controls: $\mathrm{T}=28.77 \mathrm{~h}$ vs. $24.34 \mathrm{~h}$, respectively, in a dose-dependent 129 manner $(r=-0.99, \mathrm{p}<0.001$; Fig $1 A-B)$. Increasing period was associated with reduced 130 amplitude of $p C C A 1: L U C$ oscillations and an increased relative amplitude error (RAE) (Fig 1A, $131 C)$. Results were confirmed also with the reporter lines $p P R R 7: L U C$ and $p T O C: L U C$, whereby 132 the effect of $\mathrm{Mg}$ deficiency was more pronounced in the presence of $1 \%(\mathrm{w} / \mathrm{v})$ sucrose for all 133 reporter lines tested (Fig. S1). Magnesium deficiency led to reduced growth; the fresh biomass 134 of 15 days old seedlings was about $23 \%$ less than the biomass of seedlings grown under 135 sufficient $\mathrm{Mg}$ supply (Fig $1 D-E$ ). Dry biomass was significantly reduced $(P<0.001)$ and the 136 internal Mg status of seedlings was significantly lower $(P<0.001)$ when external Mg was limited 137 (Fig 1F-G). 
138 To test if increased circadian period is linked to growth inhibition provoked by Mg shortage, seedlings were grown under $\mathrm{N}$ deficiency, which is also a major macronutrient. Seedlings fully supplied $(10 \mathrm{mM})$ or starved $(0.01 \mathrm{mM})$ with $\mathrm{N}$ had a similar free-running circadian period under either conditions: $\mathrm{T}=24.3 \mathrm{~h}$; vs. $24.3 \mathrm{~h}$ (Fig. S2A-B). Yet, RAE of pCCA1 oscillations was affected by low-N supply (Fig. S2C-D) and seedlings had morphology and size characteristic of severe $\mathrm{N}$ deficiency (Figure S2E). These results show that severe growth inhibition induced by nutrient deficiency and circadian period lengthening are not correlated.

The effect of $\mathrm{Mg}$ nutrition on circadian phase was determined in light/dark cycles (12/12) in seedlings sown on different concentrations of $\mathrm{Mg}$ (Fig. 2). In light/dark cycles TOC1 is often timed to dusk, and consistent with that no effect of $\mathrm{Mg}$ or sucrose on the phase of pTOC1:LUC activity was found (Fig. 2A). The phase of peak activity of both pCCA1:LUC and $p P R R 7: L U C$ was advanced by more than one hour by exogenous sucrose similar to previous observations (Fig. 2A) (Haydon et al., 2013; Frank et al., 2018). In the absence of added sucrose depletion of Mg resulted in a phase delay of both $p C C A 1: L U C$ and $p P R R 7: L U C$ activity, however, in the presence of added 1\% sucrose only the phase of $p P R R 7: L U C$ activity was sensitive to $\mathrm{Mg}$ status (Fig. 2A). It appears that $P R R 7$ is the most plastic component during the circadian cycle of Arabidopsis responding to $\mathrm{Mg}$ depletion. To examine this observation further, $p P R R 7: L U C$ activity was measured in a 12/12 hour light/dark cycle over the course of four days under different Mg supply. A dose dependent effect of $\mathrm{Mg}$ on the phase of $p P P R 7: L U C$ was strongest in the presence of $1 \%$ added sucrose but was also observed in the absence of added sucrose (Fig. $2 B-C$ ). We conclude that there is a plastic response of the circadian oscillator to $\mathrm{Mg}$ in diel cycles of light and dark, with $P R R 7$ being the most plastic component having a phase delay in response to low Mg. Despite the phase delay of $p P R R 7: L U C$ due to $\mathrm{Mg}$ shortage, the phase of the circadian oscillator was not altered and the estimated period was approximately 24 hours under all concentrations tested due to the forcing light/dark cycle (Fig. S3).

\section{Induction of a Mg deficiency-marker is congruent with circadian clock alteration}

164 Neither a difference in circadian oscillations nor an effect on plant growth was observed when seedlings were supplied with $200 \mu \mathrm{M} \mathrm{Mg}$ or $1,500 \mu \mathrm{M} \mathrm{Mg}$ (Fig. 1A-E). Therefore, it was tested whether a more rapid $\mathrm{Mg}$-deficient status in plants could be induced upon pre-cultivation on $200 \mu \mathrm{M} \mathrm{Mg}$ in comparison to the usually used 1,500 $\mu \mathrm{M} \mathrm{Mg}$. In fact, metabolically available Mg concentrations in plant cells are relatively high (15-25 mM) and the vacuolar storage is reported 
170

171

172

173

174

175

176

177

178

179

180

181

182

or $200 \mu \mathrm{M} \mathrm{Mg}$ and thereafter transferred to $\mathrm{Mg}$-deficient medium (5 $\mu \mathrm{M})$ for another five days in LL (Fig. S4A). Seedlings transferred to $5 \mu \mathrm{M} \mathrm{Mg}$ were pale and produced significantly less biomass only when pre-cultured on $200 \mu \mathrm{M} \mathrm{Mg}$ (Fig. S4B-C). CAX3-transcript levels were low and comparable between 1,500 $\mu \mathrm{M}$ and $200 \mu \mathrm{M} \mathrm{Mg}$ control conditions (Fig. S4D). In seedlings subjected to $5 \mu \mathrm{M}$ after being pre-cultured on $1,500 \mu \mathrm{M} \mathrm{Mg}, C A X 3$ transcript levels increased 72 $\mathrm{h}$ after $\mathrm{Mg}$ removal (Fig. 3A). But, in seedlings pre-cultured on $200 \mu \mathrm{M} \mathrm{Mg} \mathrm{CAX3} \mathrm{expression}$ was already induced after $48 \mathrm{~h}$ of treatment (Fig. 3B). Apparently, a supply with $1,500 \mu \mathrm{M} \mathrm{Mg}$ provides enough $\mathrm{Mg}$ storage to prevent $\mathrm{Mg}$ deficiency within the first three days of deprivation. However, when seedlings were entrained on $200 \mu \mathrm{M} \mathrm{Mg}$ the removal of $\mathrm{Mg}$ induced a more rapid and severe response towards deficiency stress (Fig. 3B, Fig. S4B-C). Therefore, $200 \mu \mathrm{M}$ $\mathrm{Mg}$ was chosen as a new control concentration to entrain seedlings and to investigate the time course of clock alteration and induction of Mg deficiency.

In seedlings entrained on medium with $200 \mu \mathrm{M} \mathrm{Mg}$, mean CCA1 transcript levels decreased 2fold 48-72 $\mathrm{h}$ after being transferred to $5 \mu \mathrm{M} \mathrm{Mg}$ (Fig. 3C), which coincided with the significant increase in pCCA1:LUC period induced by $\mathrm{Mg}$ deficiency (Fig $3 D$ ). Severe $\mathrm{Mg}$ deficiency (5 $\mu \mathrm{M}$ $\mathrm{Mg}$ ) caused a circadian response one day in LL after the transfer (Fig. 3E). Thereby, CCA1 expression decrease appeared at the same time point as the expression increase of $C A X 3$ mRNA, an indicator for Mg status of the plant (Fig. 3B).

\section{Light plays a critical role on the circadian effects of Mg deficiency}

Some circadian alterations are manifested in a light conditional manner (Hicks et al., 1996). To test the role of light in the response of the circadian oscillations in $A$. thaliana to $\mathrm{Mg}$, seedlings were entrained to either 8/16-h light/dark cycles (short days: SD) or 16/8-h light/dark cycles (long days: $\mathrm{LD}$ ). In SD, the biomass of Mg deficient seedlings was $59 \%$ reduced in comparison to the respective control seedlings and in LD the reduction was $81 \%$ (Fig. 4A). Circadian oscillations of pCCA1:LUC were monitored after release into LL. Similar to 12/12 $\mathrm{h}$ light/dark entrainment, $\mathrm{Mg}$ deficiency increased the period and RAE of $p C C A 1: L U C$ oscillations for both entrained photoperiods. However, the effect on period was stronger in seedlings entrained to LD conditions (Fig. 4B-D). In fact, Mg deficiency had no effect on period after plants were released to constant darkness (DD) (Def: $\mathrm{T}=24.16 \mathrm{~h}$ vs. Ctr: $\mathrm{T}=24.17 \mathrm{~h}$ ) (Fig. $4 E-F)$ that suggests a light dependence of the response of the oscillator to $\mathrm{Mg}$ deficiency. After seedlings were released into DD circadian activity was dampened after $48 \mathrm{~h}$ in darkness (Fig. $4 E$ ) but rhythms sustained for the duration of the experiment, which probably results from the presence of $1 \%$ sucrose in the culture medium (Table S1) (Dalchau et al., 2011). 

deficiency

205 To investigate whether the effect of Mg depletion was due to an inhibition of photosynthesis, we examined the effects of $\mathrm{Mg}$ in the presence or absence of 3-(3,4-dichlorophenyl)-1, 1dimethylurea (DCMU), an inhibitor of the photochemical activity of photosystem II. Experiments were performed in the presence of $1 \%$ sucrose as we observed that $\mathrm{Mg}$ depletion in the presence of sucrose has a strong effect on circadian period. Therefore, including sucrose in the medium allows to examine direct effects of photosynthetic inhibition, such as retrograde 211 signalling, rather than effects caused by sugar depletion due to inhibited photosynthesis 212 (Haydon, 2013). If Mg affects the circadian period when photosynthesis is inhibited by DCMU, 213 and sugars are buffered by $1 \%$ sucrose in the medium, then the effect must occur through 214 pathways not related to photosynthesis.

215 In the presence of sucrose, DCMU has little or no effect on circadian period (Fig. 5) as reported 216 previously (Haydon et al., 2013; Takahashi et al., 2015). Magnesium deficiency profoundly 217 affected the circadian period in the presence or absence of DCMU when sucrose was added to 218 the medium. Hence, the effect of $\mathrm{Mg}$ on the oscillator might not be due to the inhibition of 219 photosynthesis and associated downstream processes (Fig. 5B,E). The attempt to examine the 220 effect of DCMU combined with Mg deficiency in the absence of added sucrose resulted in a 221 strong effect of DCMU on plant performance and health making it impossible to detect circadian 222 rhythms (Fig. S5).

\section{External Mg supply is unlikely to be an entrainment stimulus}

224 To determine whether Mg could act as a clock regulator in plants, a $4 \mathrm{~h}$ long pulse was applied 225 with $10 \mathrm{mM} \mathrm{Mg}$ in intervals of $3 \mathrm{~h}$ to seedlings that had been entrained with $50 \mu \mathrm{M} \mathrm{Mg}$ 226 (insufficient concentration, see Fig. 1) for eight days. Under those conditions, a Mg pulse did not cause a phase shift of pCCA1:LUC peak expression at any time point (Fig. 6A). It can be concluded that $\mathrm{Mg}$ is unlikely to be a zeitgeber for the circadian clock in Arabidopsis. However, the applied Mg pulse decreased the RAE at all the time points (Fig. 6B) and full resupply of Mg

230 to deficient seedlings restored rhythmicity independent at which time of day $\mathrm{Mg}$ was resupplied 231 (Fig. 6C). When seedlings were grown on medium overly supplied with $\mathrm{Mg}$, there was no effect 232 on circadian period in the presence or absence of $1 \%$ sucrose (Fig. S6). Thus, sufficient Mg 
supply seems necessary to maintain proper functioning of the circadian oscillator but is not associated with entrainment.

\section{Simulations in a model of the Arabidopsis circadian oscillator suggests that Mg globally} affects the kinetics of the circadian oscillator

A mathematical model (De Caluwé et al., 2016) was used to gain further insight concerning the mechanism underlying the impact of $\mathrm{Mg}$ nutrition on the circadian oscillator. With the default parameter values (kinetics rates), the model simulates the behaviour of wild type plants in control conditions assuming sufficient supply with Mg. First, single parameters were changed to see whether the predicted circadian period was comparable to what was observed under $\mathrm{Mg}$ deficiency in free-running conditions. When modelling reduced PRR5/TOC1 protein degradation (Fig. S7A) or reduced PRR7/PRR9 RNA synthesis (Fig. S7B), higher expression of CCA1/LHY was predicted by the model while experimentally, Mg deficiency decreased CCA1 transcript levels (Fig. 3C). Reduced RNA synthesis of the ELF4/LUX evening complex lowered the amplitude of CCA1/LHY mRNA oscillations but did not predict an increase in circadian period (Fig. S7C). These results, together with other simulations of single parameter changes (not shown), did not reproduce simultaneously the decreased amplitude of CCA1 and the increased period observed experimentally. We then tested if alterations in overall kinetic parameters such as rates of transcription, translation and protein degradation could lead to the observed tendencies. The model predicted very long free-running periods and damped oscillations in response to reduced global rates of mRNA and protein synthesis as well as protein degradation rates (Fig $7 A$ ) resembling the experimental observations under $\mathrm{Mg}$ deficiency (Fig $1 A)$. The model predicted a restoration of amplitude and a decrease in circadian period of CCA1/LHY activity rhythms when $\mathrm{Mg}$ was reintroduced (Fig $7 A$ ), which is in accordance with experimental data (Fig. 6C) and confirms the necessity of $\mathrm{Mg}$ to maintain circadian period in Arabidopsis.

257 Thus, alterations in global rates of transcription, translation and protein degradation are likely to be affected by Mg deficiency, provoking an increase in circadian period.

259 The simulated PRC based on global changes in transcription and translation rate does not 260 predict a significant phase shift in response to a Mg pulse (Fig. 7B), which rules out Mg as a 261 zeitgeber for the circadian oscillator and is in line with experimental data (Fig. 6A).

262 A translation inhibition assay using cycloheximide ( $\mathrm{CHX})$ was performed combined with different $263 \mathrm{Mg}$ concentrations to test the model prediction that a global decrease in translation could 264 account for the experimental results. The application of $0.5 \mu \mathrm{g} \mathrm{mL} \mathrm{m}^{-1} \mathrm{CHX}$ increased the 
circadian period of pCCA1:LUC and its respective RAE (Fig. 8). The translation inhibitor had a stronger effect on period at low Mg concentrations, independent whether external sucrose was supplied or not (Fig. 8A,C). Two-Way ANOVA at a confidence interval of $95 \%$ confirmed a significant correlation between period increased under $\mathrm{Mg}$ deficiency and its further increase through translation inhibition when $1 \%$ sucrose was present in the medium $(p<0.05)$. The synergistic interaction between $\mathrm{Mg}$ deficiency and $\mathrm{CHX}$ suggest that both affect the circadian system by interfering with translational processes supporting the prediction that $\mathrm{Mg}$ deficiency has global effects on kinetics of the circadian oscillator.

\section{Discussion}

274 Magnesium is essential for multiple processes in plants. It is highly important for photosynthesis 275 where it is bound in the chloroplast as a key compound of the energy transfer in chlorophyll 276 (Lilley et al., 1974; Strasser and Butler, 1977; Walker and Weinstein, 1991). Additionally, it is 277 crucial for sucrose loading into the phloem and its partitioning from source leaves to sink plant 278 organs. Also, $\mathrm{Mg}$ is vital to the cellular energy metabolism and sustaining the ribosome structure 279 and is therefore important for protein translation (Chen et al., 2017). In the present study, it was 280 shown that $\mathrm{Mg}$ deficiency increased the circadian period of $p C C A 1: L U C, p P R R 7: L U C$ and pTOC1:LUC in a dose-dependent manner in Arabidopsis seedlings under constant light and the effect on period was greater when $1 \%$ exogenous sucrose was supplied. (Fig. 1A, Fig. S1). Period increase due to $\mathrm{Mg}$ deficiency was even more pronounced when seedlings were entrained to long day conditions before release into continuous light (Fig. 4B). Within the experimental set-up $\mathrm{Mg}$ was supplied as $\mathrm{MgSO}_{4}$. Under deficient conditions $\mathrm{Na}_{2} \mathrm{SO}_{4}$ or $\mathrm{K}_{2} \mathrm{SO}_{4}$ were added to the medium to avoid sulphur deficiency following $\mathrm{MgSO}_{4}$ restriction. To exclude higher $\mathrm{Na}^{+}$or $\mathrm{K}^{+}$concentrations as being the cause for the observed period increase, $\mathrm{MgCl}_{2}$ was used as $\mathrm{Mg}^{2+}$ source, which resulted in an increase of circadian period (Fig. S8) confirming $\mathrm{Mg}$ depletion being the cause of period increase.

An increase of circadian period caused by iron deficiency was shown to result from disordered photosynthetic functioning (Chen et al., 2013; Salomé et al., 2013). Sugars deriving from photosynthesis feed into the circadian clock, defining a metabolic dawn and adjusting the phase of CCA1 expression (Haydon et al., 2013). Inhibition of photosynthesis lengthens the circadian 294 period as does constant dim light (Haydon et al., 2013). Here, period lengthening caused by $\mathrm{Mg}$ 295 deficiency was dependent on light signalling (Fig. 4) but the observed effects were not due to 296 direct effects of $\mathrm{Mg}$ deficiency on photosynthesis. In the presence of DCMU to inhibit 
297 photosynthesis and $1 \%$ sucrose to buffer changes in associated sugar production, we found 298 that $\mathrm{Mg}$ deficiency had a profound effect on the circadian period of pCCA1:LUC oscillations 299 (Fig. 5). Because Mg deficiency could affect the oscillator when photosynthesis was impaired 300 and when changes in the sugar production are buffered, we conclude that $\mathrm{Mg}$ might affect the 301 oscillator through other pathways. That the effect of $\mathrm{Mg}$ is greater in the presence of added 302 sucrose suggests an association with some energy dependent mechanism.

303 The phase of the circadian oscillator entrains through signals that regulate its individual 304 components based on their temporal availability. Magnesium deficiency induced a phase delay 305 of $p$ PRR7:LUC peak expression in 12/12 h light/ dark cycles (Fig. 2, S3). Interpretation of the 306 timing of LUC signals must be treated with caution as peak of expression is a product of both, 307 promoter activity as well as the rate of LUC translation and folding. However, because the 308 entrained phase of $p P R R 7: L U C$ was more sensitive to Mg levels than either pCCA1:LUC or 309 pTOC1:LUC it might be an example of dynamic plasticity of the circadian oscillator in response 310 to its environment (Webb et al., 2019). Dynamic plasticity refers to the plasticity of oscillator 311 period and phase to environmental signals and the ability of the oscillator to keep internal time 312 keeping in synchrony with its environment. Thereby, the individual components of the circadian 313 oscillator are not tightly linked and the relative timing of peak expression between individual 314 components can be plastic up to a certain degree in response to a stimulus (Flis et al., 2016). 315 The effect of $P R R 7$ timing is notable because while increasing light intensity and different 316 sugars shorten the period in wild-type plants (Farré et al., 2005; Haydon et al., 2013) and 317 nicotinamide lengthens the period (Mombaerts et al., 2019), these responses are absent in prr7 318 mutants. The oscillator receives competing signals throughout a cycle of which the "strongest" 319 signal determines the phase of the oscillator. CCA1 and TOC1 genes are more locked to dawn 320 and dusk (Fig. 2A) making light the determining signal. However, as the oscillator components 321 are not locked to each other, this might assign $P R R 7$ as the light-independent regulating 322 component in the central oscillator that can respond to external changes and feeds this 323 information into the circadian timekeeping. But Mg does not influence the phase of the oscillator, 324 which excludes $\mathrm{Mg}$ as a zeitgeber signal and oscillator phase is strongly determined by light 325 regime. Furthermore, CCA1 expression is induced by sucrose that sets the phase of CCA1 326 peak expression at dawn and is advanced in the presence of exogenous sugars (Haydon et al., 327 2013). Data in Fig. $2 A$ confirm this observation where CCA1 peaked at an earlier phase in the 328 presence of sucrose under either Mg supply. Sucrose stabilizes circadian oscillations (Haydon 329 et al., 2013; Philippou et al., 2019) as the metabolite enhances the binding of PIF transcription 
factors to CCA1 promotor region and correlates with increasing transcript abundance of CCA1 (Shor et al., 2017).

Circadian oscillations in plants are generated through transcriptional/translational feedback loops whereby sucrose increases translation rates and global protein abundance (Osuna et al., 2007). Proper function of the clock does rely on a diel cycle of transcriptional control (Flis et al., 2016) plus the level of ribosomal loading driven by the circadian clock (Missra et al., 2015). Light induces proteome wide changes in protein abundance in correlation with their transcript abundance depending on the length of photoperiod whereby long days increase the abundance of several photosynthetic proteins that further affected protein abundances of downstream processes (Seaton et al., 2018). Magnesium is a very important co-factor required for translation/ protein synthesis (Chen et al., 2017). It stabilizes ribosomal structure (Klein et al., 2004) and is required for ribosome activity and translation (Weiss and Morris, 1973; Sperrazza and Spremulli, 1983). Inhibiting translation increases the circadian period of CCA1:LUC in Ostreococcus (Feeney et al., 2016) similar to the effect of $\mathrm{Mg}$ depletion reported here under continuous light. Feeney et al. (2016) demonstrated that a high endogenous Mg level increased translation rates in Ostreococcus and circadian oscillations of $\mathrm{Mg}$ levels in those cells correlate with circadian dependent translation rates. Light-signalling contributes to photoperioddependent changes in gene expression at dawn because of the impact of light on transcript abundance (Flis et al., 2016). An interference of transcriptional and translational processes by Mg deficiency might lengthen the period of the circadian oscillator in Arabidopsis in free running conditions where dawn and dusk are absent as strong entrainment signals. This is in accordance with a simulated increase in period obtained by a mathematical model assuming that $\mathrm{Mg}$ deficiency impacts overall kinetic parameters like translation rate, transcription rate and rates of protein degradation (Fig 7A). In support of the model's prediction, low doses of the translation inhibitor $\mathrm{CHX}$ synergistically increased the circadian period of pCCA1:LUC activity with Mg deficiency (Fig. 8), which is in line with the results obtained in Ostreococcus and human cells (Feeney et al., 2016). Modelling Mg resupply to deficient seedlings decreased the circadian period as well as restored rhythmicity (Fig 7A) and was also shown experimentally (Fig. 6C). Under excess Mg supply a period length of nearly $24 \mathrm{~h}$ was maintained (Fig. S6). Both underline the importance of $\mathrm{Mg}$ as a crucial cofactor for processes related to circadian timekeeping such as transcriptional/translational control. 


\section{Conclusion}

Magnesium is essential for proper timekeeping in Arabidopsis thaliana. We find that insufficient Mg supply increases circadian period and causes phase delay in light/ dark cycles. Our data suggest that one mechanism by which Mg deficiency can affect the oscillator might be through interference with global translational/ transcriptional processes. Whilst Mg deficiency can affect circadian function we find no evidence that changes in Mg levels can act as zeitgeber setting

367 circadian time.

\section{Material and Methods}

\section{Plant material and growth conditions}

370 Arabidopsis thaliana wild type seeds and reporter lines pCCA1:LUC, pPRR7:LUC and 371 pTOC1:LUC were all in Columbia-0 ecotype background. Detailed description about luciferase372 expressing construct is available elsewhere (Salomé and McClung, 2005). Seeds were 373 sterilized as previously described (De Caluwé et al., 2017), individually plated on self-prepared 374 Murashige and Skoog medium adapted from Hermans et al. 2010a, solidified with $0.5 \%$ Mg375 free high gel strength agar (Sigma-Aldrich, Germany) and supplied with different concentrations 376 of $\mathrm{Mg}$ (Table S1). Thereby, no sucrose or $1 \%$ sucrose was added to the media, respectively. 377 After stratification for two days in the dark at $4^{\circ} \mathrm{C}$, seedlings were entrained for $8-11$ days to 378 different photoperiods with white light $\left(\sim 100 \mu \mathrm{mol}\right.$ photons $\left.\mathrm{m}^{2} \mathrm{~s}^{-1}\right)$ under constant temperature 379 of $19^{\circ} \mathrm{C}$ (Panasonic MLR-352-PE, Netherlands). Seedlings were entrained to the respective Mg 380 concentration from germination on unless stated otherwise. Treatment with DCMU was done as 381 described elsewhere (Haydon and Webb, 2016). For PRC, Mg-deprived seedlings (50 $\mu \mathrm{M})$ were 382 transferred to medium containing $10 \mathrm{mM} \mathrm{Mg}$ for $4 \mathrm{~h}$ in $3 \mathrm{~h}$ intervals and subsequently returned 383 to entrainment medium. For the Mg resupply assay, Mg deprived seedlings were resupplied in 3 $384 \mathrm{~h}$ intervals by transferring seedlings to medium containing $3 \mathrm{mM} \mathrm{Mg}$ (Fig. S9). The PRC was 385 calculated as descripted previously (Johnson, 1992).

387 Arabidopsis Col-0 seedlings were cultivated, as described above, on media supplemented with 388 either $200 \mu \mathrm{M}$ or $5 \mu \mathrm{M}$ Mg from germination on. Fifteen pooled seedlings were harvested in the 389 morning (ZT4) on days 8 to 12, rinsed three times in deionized water, carefully cleaned for left390 over agar medium and dried at $70{ }^{\circ} \mathrm{C}$ for $72 \mathrm{~h}$. Dried plant material was digested in $500 \mu \mathrm{L} 35 \%$ $391(\mathrm{v} / \mathrm{v}) \mathrm{HNO}_{3}$ at $90{ }^{\circ} \mathrm{C}$ for $1 \mathrm{~h}$. From the digest, $200 \mu \mathrm{L}$ was diluted in $7 \mathrm{~mL}$ Milli-Q water and 
392 filtered. The mineral concentrations were determined by NexION 350 S ICP-MS (PerkinElmer). 393 Indium was used as internal standard to correct for instrument instability and oxide 394 interferences.

395 Luciferase experiments and rhythms analysis

396 Seedlings were sprayed with $2 \mathrm{mM}$ Luciferin (VivoGlo ${ }^{\mathrm{TM}}$ Luciferin, In Vivo Grade, Promega, 397 Netherlands) one day before they were released either into continuous light or dark. Following 398 the dosing, seedlings were individually transferred to 96-well opaque white microplates (23300, 399 Berthold, Germany) containing $150 \mu \mathrm{L}$ of the respective liquid growth medium plus $2 \mathrm{mM} \mathrm{D}$ 400 Luciferin. Microplates were sealed with transparent EASYseal sealing film 120x80 mm (Greiner 401 bio-one, Germany) that was punctured $(\sim 1.0 \mathrm{~mm} \varnothing)$ to allow gas exchange. Luminescence was 402 detected at $590 \mathrm{~nm}$ for 5-10 s hourly after $120 \mathrm{~s}$ in darkness using a multimode microplate 403 reader (TriSta ${ }^{\mathrm{r} 2}$ LB942 Berthold, Germany). Data were processed with MikroWin ${ }^{\mathrm{TM}}$ software v. 4045.21 (Labsis Laborsysteme, Germany) and rhythms of LUC activity were analysed with 405 BioDare2 beta (https://biodare2.ed.ac.uk/) (Zielinski et al., 2014). Period and RAE estimates 406 were calculated on rhythms between 24-120 h in continuous light on non-normalized data using 407 Fast- 527 Fourier Transformed Non-Linear Least Squares (FFT-NLLS) after linear detrending.

408 RNA Isolation and RT-qPCR

409 Total RNA was isolated from $100 \mathrm{mg}$ frozen ground tissues of whole seedlings. RNA was 410 purified with Maxwell ${ }^{\circledR} 16$ LEV Plant RNA Kit (Promega, Benelux BV) using Maxwell ${ }^{\circledR} 16$ 411 AS2000 Instrument (Promega, Benelux BV) according to the manufacturer's recommendation. 412 Quality and purity of the samples were verified with a NanoDrop 2000 UV-Vis 413 Spectrophotometer (Thermo Scientific, Loughborough, UK). cDNA was synthesized from one $\mu \mathrm{g}$ 414 RNA with GoScript ${ }^{\mathrm{TM}}$ Reverse Transcription System (Promega, Benelux BV) and thereafter 415 diluted to 1:30 (v/v) with autoclaved nuclease-free water for quantitative real time PCR (qPCR). 416 qPCR was carried out in 96-well microplates in the PikoReal real time PCR system (Thermo 417 Scientific, Loughborough, UK). Each reaction contained $5 \mu \mathrm{L}$ of $2 x$ SYBR Green mastermix 418 (Promega, Benelux BV), $2.5 \mu \mathrm{L}$ primer mix (forward and reverse, $2.5 \mu \mathrm{M}$ each) and 2.5 $\mu \mathrm{L}$ 1:30 419 diluted cDNA. Thermocycles were as followed: pre-incubation at $95^{\circ} \mathrm{C}$ for $3 \mathrm{~min}, 40$ cycles at

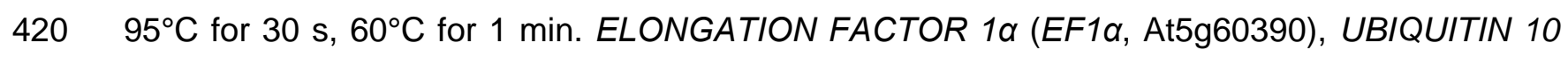
421 (UBQ10, At4g05320) and CYCLIN-DEPENDENT KINASE A;1 (CDKA, At3g48750) were used 
422 as reference genes. Oligo nucleotide sequences and their respective efficiencies are given in 423 Table S2.

424 Mathematical Modelling

425 A previously developed model (De Caluwé et al., 2016) of the core oscillator was used to 426 investigate the mechanisms of $\mathrm{Mg}$ input to the clock. The model consists of eight differential 427 equations describing the evolution of mRNA and protein concentrations of four pairs of clock 428 genes: CCA1/LHY, PRR9/PRR7, PRR5/TOC1, and ELF4/LUX. The kinetic parameters 429 represent synthesis rates, degradation rates, and enzymatic constants. The full equations and 430 parameter values for the model are described elsewhere in detail, along with a description of the 431 building and optimization process (De Caluwé et al., 2016). We used the original parameter 432 values to represent plants fully supplied with $\mathrm{Mg}$. The intermediate- and low-Mg conditions were 433 modelled by simulating by reducing the mRNA and protein synthesis rates by a factor of 0.5 434 (intermediate-Mg) or 0.35 (low-Mg), and the protein degradation rates by 0.7 (intermediate-Mg) 435 or 0.65 (low-Mg). The periods of the Mg-deficient clock were around $26 \mathrm{~h}$ (intermediate-Mg) or $43628.5 \mathrm{~h}$ (low-Mg). For modelling single parameters as an Mg input, we multiply specific kinetic 437 parameters by 0.2 (representing a reduction of $80 \%$ of their value).

438 To construct the PRC, entrainment cycles were simulated on either intermediate-Mg or low-Mg 439 conditions and, thereafter, $\mathrm{Mg}$ resupply was simulated in continuous light by restoring all 440 parameters to their initial values. The circadian phase was calculated as previously described 441 (Johnson 1992). Phase shifts were defined as the difference in circadian phase between the 442 first peaks of the treated and control simulations. All simulations were performed in MATLAB 443 (Mathworks, Cambridge). The integration of the differential equations used the external 444 CVODES solver.

Translation inhibition assay

446 For the assay, clusters of 8-10 pCCA1:LUC Col-0 seeds were sown in plastic rings sealed at the 447 base with $0.5 \mu \mathrm{m}$ nylon mesh on solid media (0.5 \% Mg-free agar) containing different 448 concentrations of $\mathrm{Mg}$ either in the presence or absence of $1 \%$ sucrose. Growth conditions were 449 the same as described earlier. Eleven days old seedlings were dosed with $2 \mathrm{mM}$ Luciferin and 450 luminescence was detected for $800 \mathrm{~s}$ hourly under LL with a Nightshade CCD camera and 451 imaging chamber (Berthold). The translation inhibitor was applied just before subjective dawn of 452 the second day LL by transferring seedlings to liquid media with the respective Mg supply 453 containing $0.5 \mu \mathrm{g} \mathrm{mL}^{-1} \mathrm{CHX}$ (dissolved in DMSO) or $0.1 \% \mathrm{DMSO}$ as solvent control. Captured 
454 data were processed with IndiGO software (Berthold) and rhythms of pCCA1:LUC were 455 analysed with BioDare2 beta (https://biodare2.ed.ac.uk/) as descripted earlier. Replicates with a 456 RAE $\geq 0.5$ were excluded from statistical analysis. A two-way ANOVA was performed followed 457 by Wilcoxon Rang Sum test to determine whether $\mathrm{CHX}$ and/ or Mg deficiency significantly alter 458 the circadian period with a confidence interval of $95 \%$.

\section{$459 \quad$ Statistical analysis}

460 All statistical analyses performed in this study were carried out in $\mathrm{R}$ software version 3.4.1. First, 461 the distribution of the residuals was checked using the functions hist and shapiro.test (packages 462 graphics and stats, respectively). Homogeneity of variances across groups was tested with 463 Levene's test (leveneTest from package car). Parametric statistics were performed (in 464 experiments with normally distributed and homoscedastic residuals) by using Two-Sample 465 Student's $t$-test with 95\% confidence interval (t.test function from package stats) to compare the 466 means between two groups of values. One-way ANOVA or factorial ANOVA were used to 467 compare the means between more than two groups (aov function from package stats). Tukey's 468 'Honest Significant Difference' (HSD) method was performed to generate a confidence interval 469 (C.I.) on the differences between multiple means being compared with either ANOVA tests 470 (TukeyHSD function from package stats). For non-parametric statistics, Kruskal-Wallis Rank 471 Sum test followed by Nemenyi post-hoc test were performed (kruskal.test and 472 posthoc.kruskal.nemenyi.test functions from packages stats and 'PMCMR', respectively).

\section{Acknowledgments}

475 We thank Dr. C. Robertson McClung (Dartmouth College) for providing the luciferase reporter 476 seeds. We are in debt with Dr. Natsuko Kobayashi and Keitaro Tanoi (University of Tokyo) for 477 the ICP-MS facility. We thank Dr. Michael Haydon (University of Melbourne) and Dr. John 478 O'Neill, for insightful discussions about luminescence and PRC data. 
Akanuma G, Yamazaki K, Yagishi Y, lizuka Y, Ishizuka M, Kawamura F, Kato-Yamada Y (2018) Magnesium suppresses defects in the formation of 705 ribosomes as well as in sporulation caused by lack of several individual ribosomal proteins. J Bacteriol. 200:18

Alabadí D, Yanovsky MJ, Más P, Harmer SL, Kay SA (2002) Critical role for CCA1 and LHY in maintaining circadian rhythmicity in Arabidopsis. Curr Biol 12: 757-761

Andrés-Colás N, Perea-García A, Puig S, Peñarrubia L (2010) Deregulated copper transport affects Arabidopsis development especially in the absence of environmental cycles. Plant Physiol 153: 170-184

Becher M, Talke IN, Krall L, Krämer U (2004) Cross-species microarray transcript profiling reveals high constitutive expression of metal homeostasis genes in shoots of the zinc hyperaccumulator Arabidopsis halleri. Plant J 37: 251-268

Cakmak I, Hengeler C, Marschner H (1994) Changes in phloem export of sucrose in leaves in response to phosphorus, potassium and magnesium deficiency in bean plants. 45 (9): 1251-1257

De Caluwé J, de Melo JRF, Tosenberger A, Hermans C, Verbruggen N, Leloup JC, Gonze D (2017) Modeling the photoperiodic entrainment of the plant circadian clock. J Theor Biol 420: $220-231$

De Caluwé J, Xiao Q, Hermans C, Verbruggen N, Leloup JC, Gonze D (2016) A compact model for the complex plant circadian clock. Front Plant Sci 7: 74 H, Yeh K-C (2013) Iron is involved in the maintenance of circadian period length in Arabidopsis. Plant Physiol 161: 1409-1420

504

Chen ZC, Peng WT, Li J, Liao H (2017) Functional dissection and transport mechanism of magnesium in plants. Semin Cell Dev Biol 74: 142-152

505 Clark FW, Washington HS (1924) The Composition of the Earth's Crust. U.S. overnment $506 \quad$ Printing Office, Washington 
Cowan JA (1998) Metal activation of enzymes in nucleic acid biochemistry. Chem Rev 98: 1067-1087

Culkin F, Cox RA (1966) Sodium, potassium, magnesium, calcium and strontium in sea water. Deep Res 13: 789-804

Dalchau N, Baek SJ, Briggs HM, Robertson FC, Dodd AN, Gardner MJ, Stancombe MA, Haydon MJ, Stan GB, Gonçalves JM, et al (2011) The circadian oscillator gene GIGANTEA mediates a long-term response of the Arabidopsis thaliana circadian clock to sucrose. Proc Natl Acad Sci U S A 108: 5104-5109

Ding Y, Luo W, Xu G (2006) Characterisation of magnesium nutrition and interaction of magnesium and potassium in rice. Ann Appl Biol 149:111-123 (2005) Plant Circadian Clocks Increase Photosynthesis, Growth, Survival, and Competitive Advantage. Science 309: 630-633

Dunlap JC (1999) Molecular bases for circadian clocks. Cell 96: 271-290

Farré EM, Harmer SL, Harmon FG, Yanovsky MJ, Kay SA (2005) Overlapping and distinct roles of PRR7 and PRR9 in the Arabidopsis circadian clock. Curr Biol 15: 47-54

Feeney KA, Hansen LL, Putker M, Olivares-Yañez C, Day J, Eades LJ, Larrondo LF, Hoyle NP, O'Neill JS, van Ooijen G (2016) Daily magnesium fluxes regulate cellular timekeeping and energy balance. Nature 532: 375-379

Fish LE, Deshaies R, Jagendorf AT, Section PB (1983) A Mg2+ requirement for rapid ATPdriven protein synthesis by intact pea chloroplasts. Plant Sci Lett 31: 139-146

Fleischer M (1954) The abundance and distribution of the chemical elements in the Earth's crust. J Chem Educ 31: 446-455

Flis A, Sulpice R, Seaton DD, Ivakov AA, Liput M, Abel C, Millar AJ, Stitt M (2016) Photoperiod-dependent changes in the phase of core clock transcripts and global transcriptional outputs at dawn and dusk in Arabidopsis. Plant Cell Environ 39: 1955-1981

533 Frank A, Matiolli CC, Viana AJC, Hearn TJ, Kusakina J, Belbin FE, Wells Newman D, 

Arabidopsis by the sugar-responsive transcription factor bZIP63. Curr Biol 28: 25972606.e6

Green RM, Tingay S, Wang ZY, Tobin EM (2002) Circadian rhythms confer a higher level of fitness to Arabidopsis plants. Plant Physiol 129: 576-584

Greenham K, McClung CR (2015) Integrating circadian dynamics with physiological processes in plants. Nat Rev Genet 16: 598-610

Grzebisz W (2009) Magnesium—food and human health. J Elem, 299-323

Gutiérrez RA, Stokes TL, Thum K, Xu X, Obertello M, Katari MS, Tanurdzic M, Dean A, Nero DC, McClung CR, et al (2008) Systems approach identifies an organic nitrogenresponsive gene network that is regulated by the master clock control gene CCA1. PNAS 105: 4939-4944

Harmer SL (2009) The circadian system in higher plants. Annu Rev Plant Biol 60: 357-377

Hauer-Jákli M, Tränkner M (2019) Critical leaf magnesium thresholds and the impact of entrainment of the Arabidopsis thaliana circadian clock. Nature 502: 689-692

Haydon MJ, Román Á, Arshad W (2015) Nutrient homeostasis within the plant circadian network. Front Plant Sci 6: 299

Haydon MJ, Webb AAR (2016) Assessing the impact of photosynthetic sugars on the Arabidopsis circadian clock. Environ Responses Plants Methods Mol Biol. doi: 10.1007/978-1-4939-3356-3_12

Hermans C, Johnson GN, Strasser RJ, Verbruggen N (2004) Physiological characterisation of magnesium deficiency in sugar beet: acclimation to low magnesium differentially affects photosystems I and II. Planta 220:344-355

Hermans C, Verbruggen N (2005) Physiological characteriza- tion of magnesium deficiency in 
Arabidopsis thaliana.J Exp Bot 56:2153-2161

562

563

564

565

566

567

568

569

570

571

572

573

574

575

576

577

578

579

580

581

582

583

584

585

586

587

588

Hermans C, Bourgis F, Faucher M, Strasser RJ, Delrot S, Verbruggen N (2005) Magnesium deficiency in sugar beets alters sugar partitioning and phloem loading in young mature leaves. Planta 220: 541-549

Hermans C, Conn SJ, Chen J, Xiao Q, Verbruggen N (2013) An update on magnesium homeostasis mechanisms in plants. Metallomics 5: 1170

Hermans C, Verbruggen $\mathbf{N}$ (2005) Physiological characterization of Mg deficiency in Arabidopsis thaliana. J Exp Bot 56: 2153-2161

Hermans C, Vuylsteke M, Coppens F, Craciun A, Inzé D, Verbruggen N (2010a) Early transcriptomic changes induced by magnesium deficiency in Arabidopsis thaliana reveal the alteration of circadian clock gene expression in roots and the triggering of abscisic acidresponsive genes. New Phytol 187: 119-131

Hermans C, Vuylsteke M, Coppens F, Cristescu SM, Harren FJM, Inzé D, Verbruggen N (2010b) Systems analysis of the responses to long-term magnesium deficiency and restoration in Arabidopsis thaliana. New Phytol 187: 132-144

Hicks KA, Millar AJ, Carré IA, Somers DE, Straume M, Meeks-Wagner DR, Kay SA (1996) Conditional circadian dysfunction of the Arabidopsis early-flowering 3 mutant. Science 274: 790-792

Hong S, Kim SA, Guerinot M Lou, Robertson McClung C (2013) Reciprocal interaction of the circadian clock with the iron homeostasis network in Arabidopsis. Plant Physiol 161: 893903

Hotta CT, Gardner MJ, Hubbard KE, Baek SJ, Dalchau N, Suhita D, Dodd AN, Webb AAR (2007) Modulation of environmental responses of plants by circadian clocks. Plant, Cell Environ 30: 333-349

Hsu PY, Harmer SL (2014) Wheels within wheels: The plant circadian system. Trends Plant Sci 19: $240-249$

Johnson CH (1992) Phase Response Curves: what do they tell use about circadian clocks?, Circadian. Hokkaido University Press, Sappora 
Kamiya T, Yamagami M, Hirai MY, Fujiwara T (2012) Establishment of an in planta magnesium monitoring system using CAX3 promoter-luciferase in Arabidopsis. J Exp Bot

Klein DJ, Moore PB, Steitz TA (2004) The contribution of metal ions to the structural stability of the large ribosomal subunit. RNA 10: 1366-79

Levitt LS (1954) The role of magnesium in photosynthesis. Science 120: 33-35

Lilley RM, Holborow K, Walker DA (1974) Magnesium activation of photosynthetic $\mathrm{CO}_{2}-$ fixation in a reconstituted chloroplast system. New Phytol 73: 657-662

McClung CR (2006) Plant circadian rhythms. Plant Cell 18: 792-803

Missra A, Ernest B, Lohoff T, Jia Q, Satterlee J, Ke K, Von Arnim AG (2015) The circadian clock modulates global daily cycles of mRNA ribosome loading. Plant Cell 27: 2582-2599

Mombaerts L, Carignano A, Robertson FC, Hearn TJ, Junyang J, Hayden D, Rutterford Z,

Osuna D, Usadel B, Morcuende R, Gibon Y, Bläsing OE, Höhne M, Günter M, Kamlage B, Hotta CT, Hubbard KE, Maria MRC, et al (2019) Dynamical differential expression

(DyDE) reveals the period control mechanisms of the Arabidopsis circadian oscillator.

PLOS Comput Biol 15: e1006674

Trethewey R, Scheible W-R, et al (2007) Temporal responses of transcripts, enzyme activities and metabolites after adding sucrose to carbon-deprived Arabidopsis seedlings. Plant J 49: 463-491

Philippou K, Ronald J, Sánchez-Villarreal A, Davis AM, Davis SJ (2019) Physiological and genetic dissection of sucrose inputs to the Arabidopsis thaliana circadian system. Genes 10: 334

Robertson FC, Skeffington AW, Gardner MJ, Webb AAR (2009) Interactions between circadian and hormonal signalling in plants. Plant Mol Biol 69: 419-427

Römheld V (2012) Diagnosis of deficiency and toxicity of nutrients. In: Marschner P (ed) Mineral nutrition of higher plants; 3rd edn. Elsevier Ltd., pp 299-311

615 Salomé PA, McClung CR (2005) Pseudo-response Regulator 7 and 9 are partially redundant 
genes essential for the temperature responsiveness of the Arabidopsis circadian clock.

Plant Cell 17: 791-803

Salomé PA, Oliva M, Weigel D, Krämer U (2013) Circadian clock adjustment to plant iron status depends on chloroplast and phytochrome function. EMBO J 32: 511-523

Seaton DD, Graf A, Baerenfaller K, Stitt M, Millar AJ, Gruissem W (2018) Photoperiodic control of the Arabidopsis proteome reveals a translational coincidence mechanism. Mol Syst Biol. 14 (3). doi: 10.15252/msb.20177962

Sperrazza JM, Spremulli LL (1983) Quantitation of cation binding to wheat germ ribosomes: Influences on submit association equilibria and ribosome activity. Nucleic Acids Res 11: 2665-2679

Strasser RJ, Butler WL (1977) Energy transfer and the distribution of excitation energy in the photosynthetic apparatus of spinach chloroplasts. BBA - Bioenerg 460: 230-238

Sweeney BM, Folli SI (1984) Nitrate deficiency shortens the circadian period in Gonyaulax. Plant Physiol 75: 242-245

Takahashi N, Hirata Y, Aihara K, Mas P (2015) A hierarchical multi-oscillator network orchestrates the Arabidopsis circadian system. Cell 163: 148-159

Verbruggen N, Hermans C (2013) Physiological and molecular responses to magnesium nutritional imbalance in plants. Plant Soil 368: 87-99

637 Walker CJ, Weinstein JD (1991) Further characterization of the magnesium chelatase in $638 \quad$ isolated developing cucumber chloroplasts. Plant Physiol 95: 1189-1196

639 Wang QM, Guan KL, Roach PJ, DePaoli-Roach AA (1995) Phosphorylation and activation of 640 the ATP-Mg-dependent protein phosphatase by the mitogen-activated protein kinase. J $641 \quad$ Biol Chem 270: 18352-18358

642 Webb AAR (2003) The physiology of circadian rhythms in plants. New Phytol 160: 281-303 
643 Webb AAR, Seki M, Satake A, Caldana C (2019) Continuous dynamic adjustment of the plant 644 circadian oscillator. Nat Commun 10: 550

645 Weiss RL, Morris DR (1973) Cations and ribosome structure. I. Effects of the 30S subunit of $646 \quad$ substituting polyamines for magnesium ion. Biochemistry 12: 435-441

647 Zielinski T, Moore AM, Troup E, Halliday KJ, Millar AJ (2014) Strengths and limitations of 648 period estimation methods for circadian data. PLoS One 9: e96462

649

650 
Fig. 1. Limiting external Mg availability alters circadian oscillations of CCA1:LUC. $(A)$ Mean circadian oscillations of pCCA1:LUC in LL conditions after being entrained to 12/12-h

654 light/dark cycles for eight days on media supplied with different $\mathrm{Mg}$ concentrations. (B) 655 pCCA1:LUC period estimates in $\mathrm{h}$ under $\mathrm{LL}$. (C) relative amplitude error of oscillations (mean \pm 656 SEM, $n=12$ ) of pCCA1:LUC. (D) Fresh biomass and $(E)$ morphological phenotype of seedlings 657 at the end of the experiment. $(F)$ dry biomass and $(G) \mathrm{Mg}$ concentration in plant tissue [mean \pm 658 SEM, $n=3$ ( $1=15$ pooled seedlings)] of 12-day-old seedlings cultivated in light/dark cycles on 659 control (Ctr.: $200 \mu \mathrm{M} \mathrm{Mg}$ ) and deficient media (Def.: $5 \mu \mathrm{M} \mathrm{Mg).} \mathrm{Significance} \mathrm{was} \mathrm{verified} \mathrm{by}(B)$ 660 Spearman's rho correlation coefficient and Kruskal-Wallis Rank Sum Test followed by Nemenyi 661 post-hoc test, (C) One-Way ANOVA followed by Tukey HSD post-hoc test and ( $F$ - $G$ ) Two662 Sample Student's $t$-test 95\% C.I. (different letters indicate significance at the level of $P<0.05$. 663 Asterisks represent significance at ${ }^{*} P<0.05$, ${ }^{\star *} P<0.01$, and ${ }^{* \star *} P<0.001$ ).
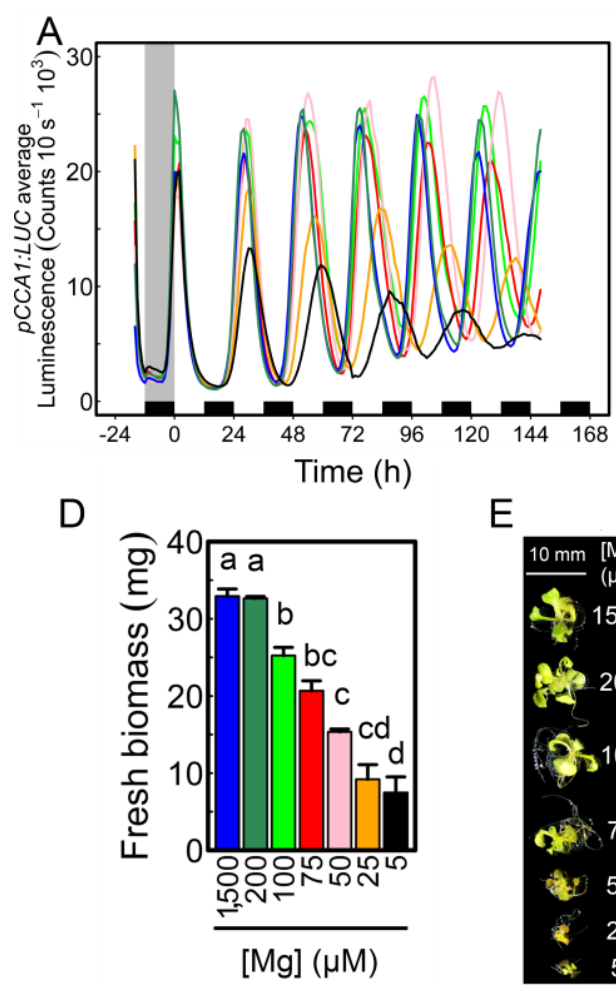

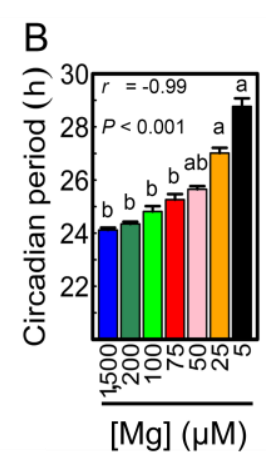

E

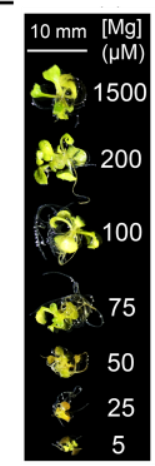

$\mathrm{F}$
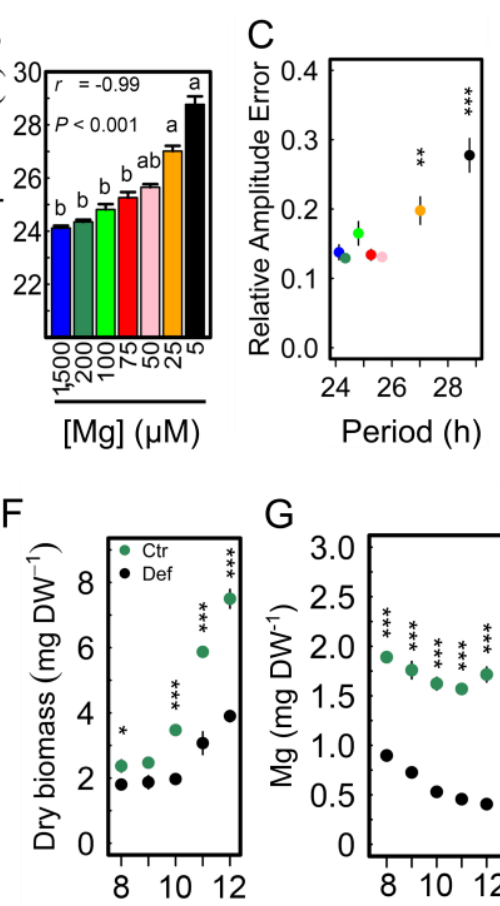

G

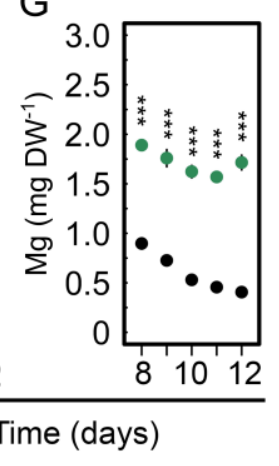


Fig. 2. Mg deficiency delays the circadian phase of PRR7. $(A)$ Circadian phase of peak

667 expression (mean \pm SEM) in 12/12 hour light/dark cycle of pCCA1:LUC, pPRR7:LUC and

668 pTOC1:LUC in 11-day-old Col-0 WT Arabidopsis seedlings $(n=20)$ in the absence or presence

669 of $1 \%$ sucrose. Circadian phase of $p P R R 7: L U C$ peak expression in a four day 12/12 hour

670 light/dark cycle under different Mg supply in the $(B)$ absence or $(C)$ presence of $1 \%$ sucrose.

671 Significance was determined by a Wilcoxon Rang Sum test. Different letters indicate

672 significance at the level of $P \leq 0.05$.

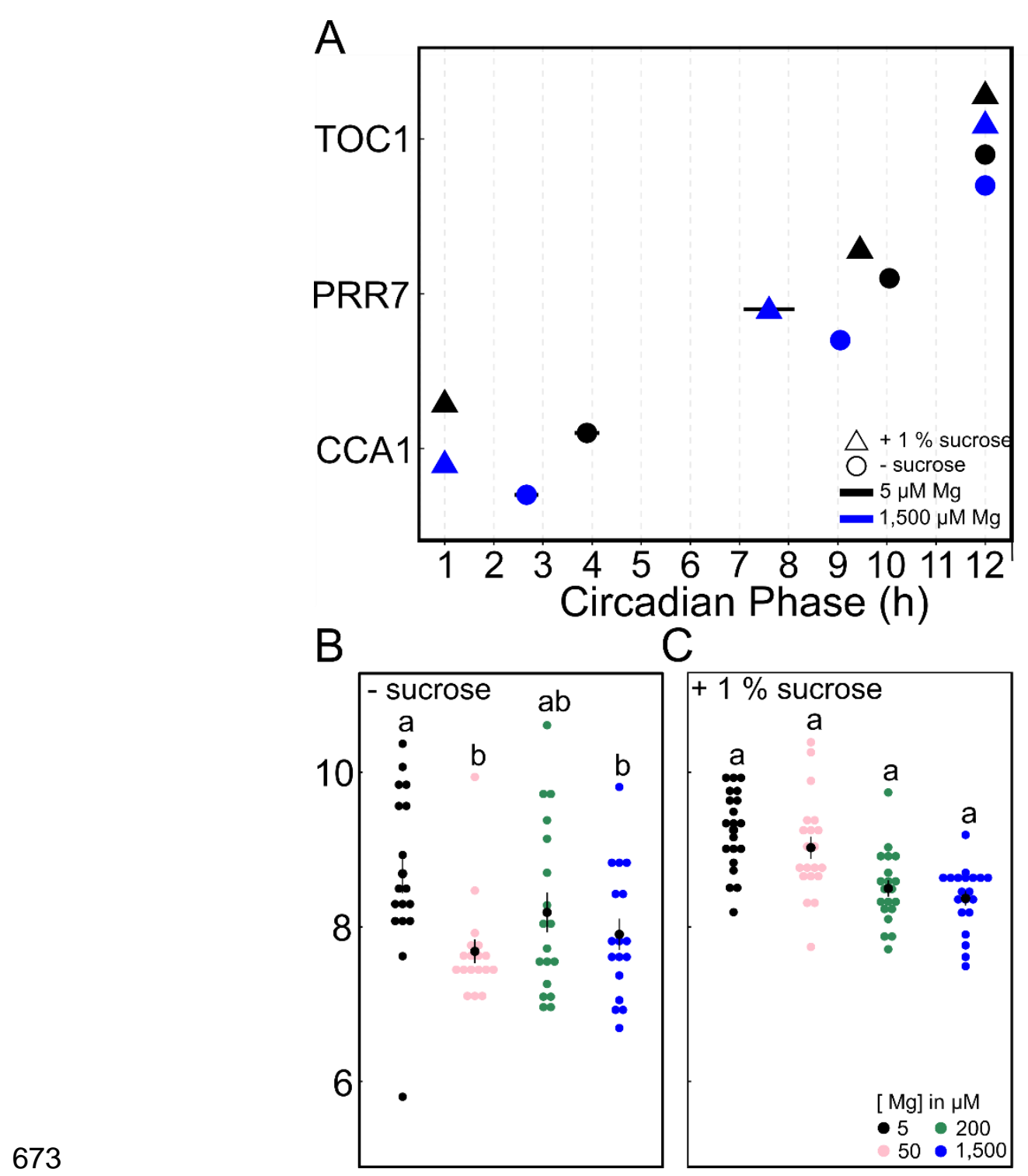


675 Fig. 3. Oscillator alteration occurs concomitantly with expression of the Mg deficiency

676 marker CAX3. Seedlings entrained for eight days to 12/12-h light/dark cycles on medium with 677200 or $1,500 \mu \mathrm{M} \mathrm{Mg}$ were transferred to fresh media either deficient in $\mathrm{Mg}(5 \mu \mathrm{M})$ or fully 678 supplied and released in continuous light. $(A)$ CAX3 mRNA expression [mean \pm SEM, $n=3(1=$ 67930 pooled seedlings)] after transfer from 1,500 $\mu \mathrm{M} \mathrm{Mg}$, (B-C) CAX3 mRNA expression and 680 CCA1 mRNA expression [mean \pm SEM, $n=3(1=30$ pooled seedlings)] after transfer from 200 $681 \mu \mathrm{M} \mathrm{Mg},(D)$ correlation between estimated circadian period and external $\mathrm{Mg}$ concentration, $(E)$ 682 average luminescence traces of pCCA1:LUC activity. Significance was verified by Pearson's 683 Product Moment correlation coefficient $(P<0.01)$ and One-Way ANOVA followed by Tukey 684 HSD post-hoc or Two-Sample Student's $t$-test at a 95\% confidence interval (asterisks represent 685 significance at ${ }^{*} P<0.05$, ${ }^{* *} P<0.01$, and $\left.{ }^{* \star *} P<0.001\right)$.

A

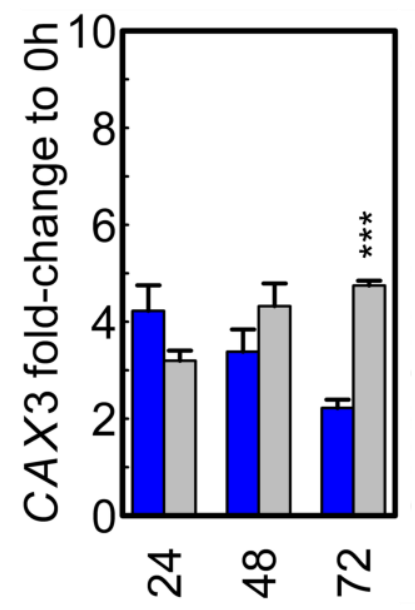

B

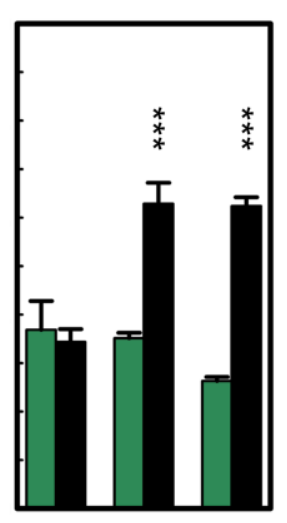

$\stackrel{\sim}{\sim} \underset{N}{N}$
C

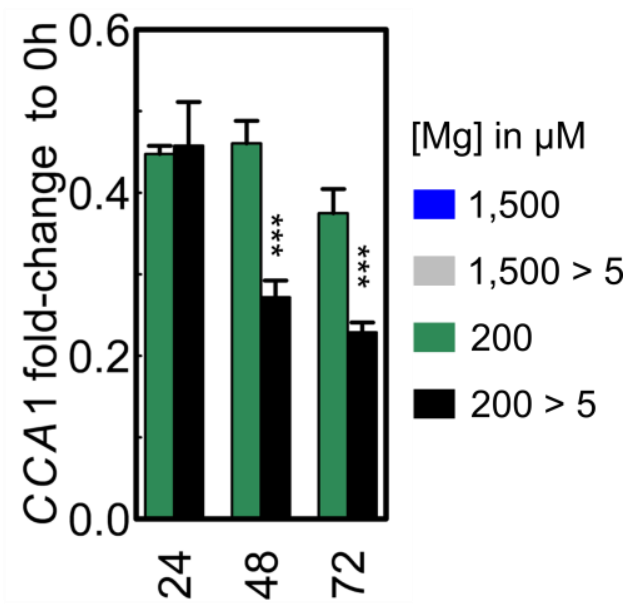

Time since Mg removal $(h)$

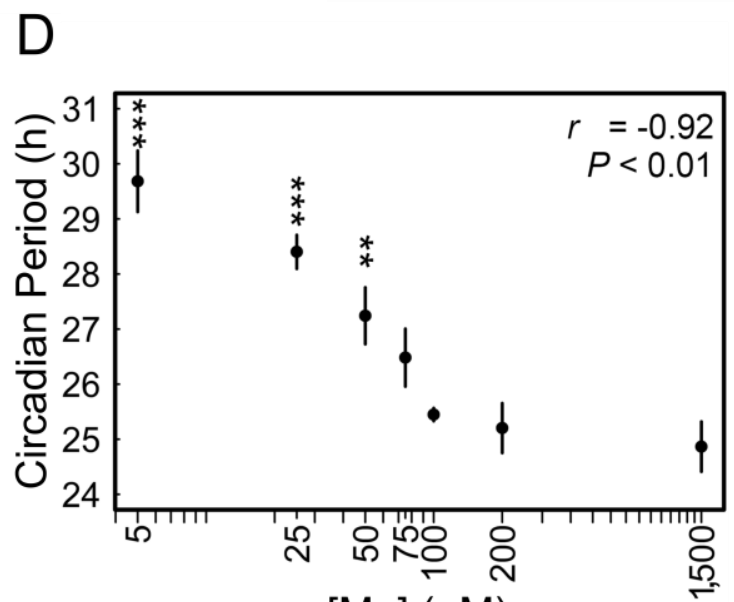

$[\mathrm{Mg}](\mu \mathrm{M})$
$\mathrm{E}$

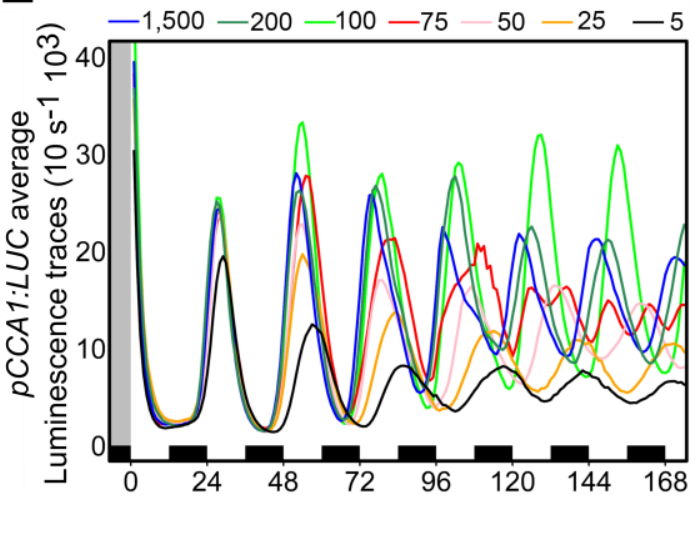

Time $(\mathrm{h})$ 
Fig. 4. Increase of circadian period due to $\mathrm{Mg}$ deficiency is light dependent. $(A)$ fresh weight (FW) biomass (mean \pm SEM, $n=3-4[1=4$ pooled seedlings]) of seedlings entrained to long day (LD) 16/8 light/dark cycles and short day (SD) 8/16 h light/dark cycles. pCCA1:LUC average luminescence traces of seedlings entrained for eight days to $(B) \mathrm{LD},(C) \mathrm{SD}$ on $\mathrm{Mg}$ 691 sufficient (Ctr.: $200 \mu \mathrm{M}$ ) and deficient (Def.: $5 \mu \mathrm{M}$ ) medium before released into LL, $(D)$ relative 692 amplitude error of LD and SD (mean \pm SEM, $n=12-48$ ). Diagonal-oriented asterisks represent 693 significance for the circadian period, vertical-oriented asterisks represent significance for relative 694 amplitude error. $(E)$ pCCA1:LUC average luminescence traces of seedlings entrained for eight 695 days to a $12 / 12 \mathrm{~h}$ light/dark cycles on Ctr. and Def. media before released into DD, $(F)$ 696 respective relative amplitude error. Significance was verified by Two-Sample Student's $t$-test at $69795 \%$ confidence interval ( $\left.{ }^{* * *} P<0.001\right)$.

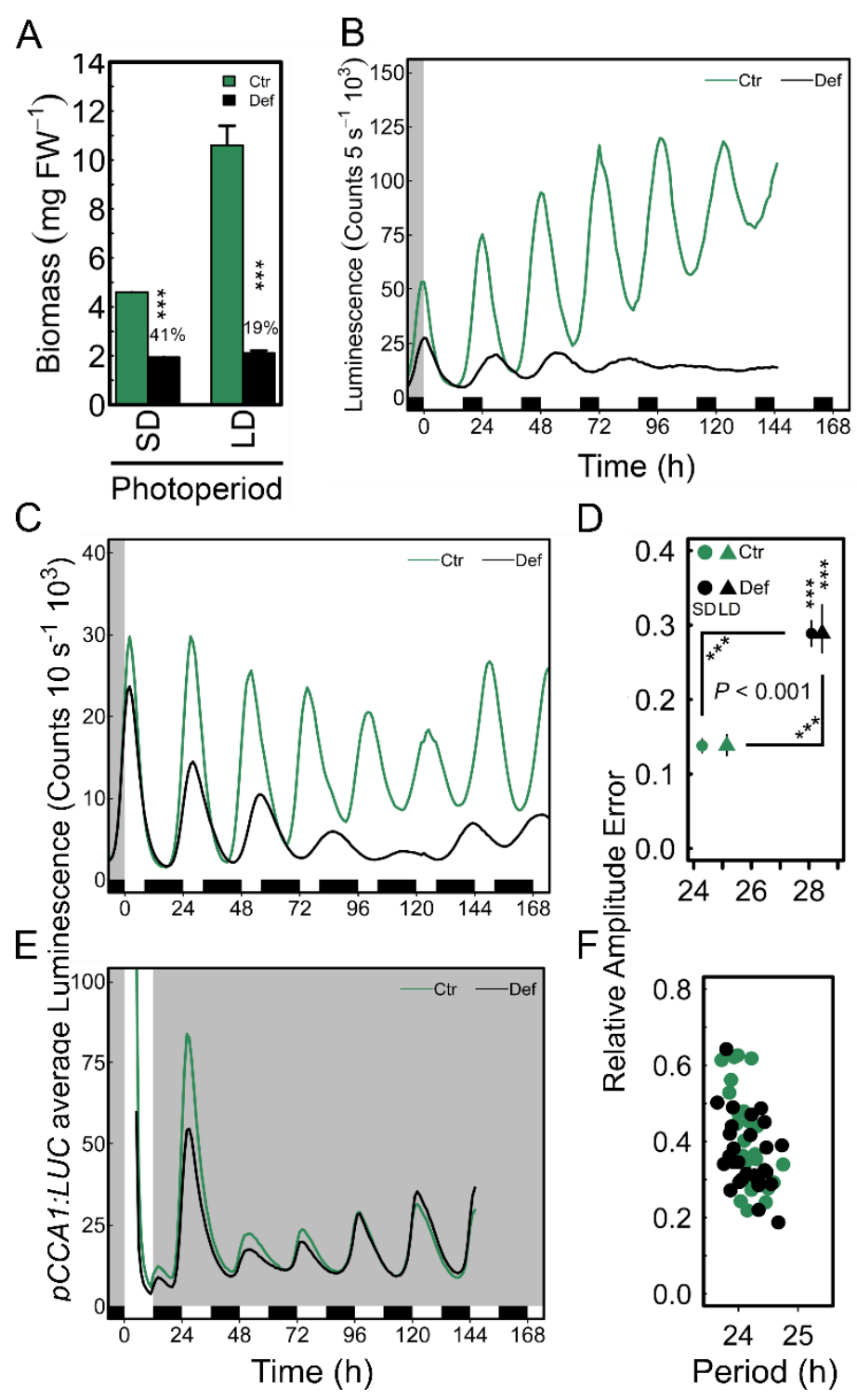

698 
Fig. 5. An active photosynthetic system is not required to detect Mg deficiencydependent circadian alterations. Seedlings entrained for eight days to 16/8-h light/dark cycles on either $200 \mu \mathrm{M}$ (Ctr) or $5 \mu \mathrm{M}$ (Def) Mg media were released into $\mathrm{LL}$ in the presence or absence of $20 \mu \mathrm{M}$ DCMU. The experiment was independently repeated [Experiment $1 \mathrm{~A}-\mathrm{C}$; Experiment $2 \mathrm{D}-\mathrm{F}] .(A, D)$ Luminescence traces of $p C C A 1: L U C+$ reporter in $L L,(B, E)$ estimated circadian period $(\mathrm{h})$ of $p C C A 1: L U C$ activity (mean \pm SEM, $n=12),(C, F)$ relative amplitude error of pCCA1:LUC oscillations (mean \pm SEM, $n=12$ ). Statistical significance was verified by factorial ANOVA followed by Tukey HSD post-hoc (different letters indicate significance at the level of $P<0.05)$. Experiments were undertaken in the laboratories at Université libre de Bruxelles $(A-C)$ and Cambridge University $(D-F)$.
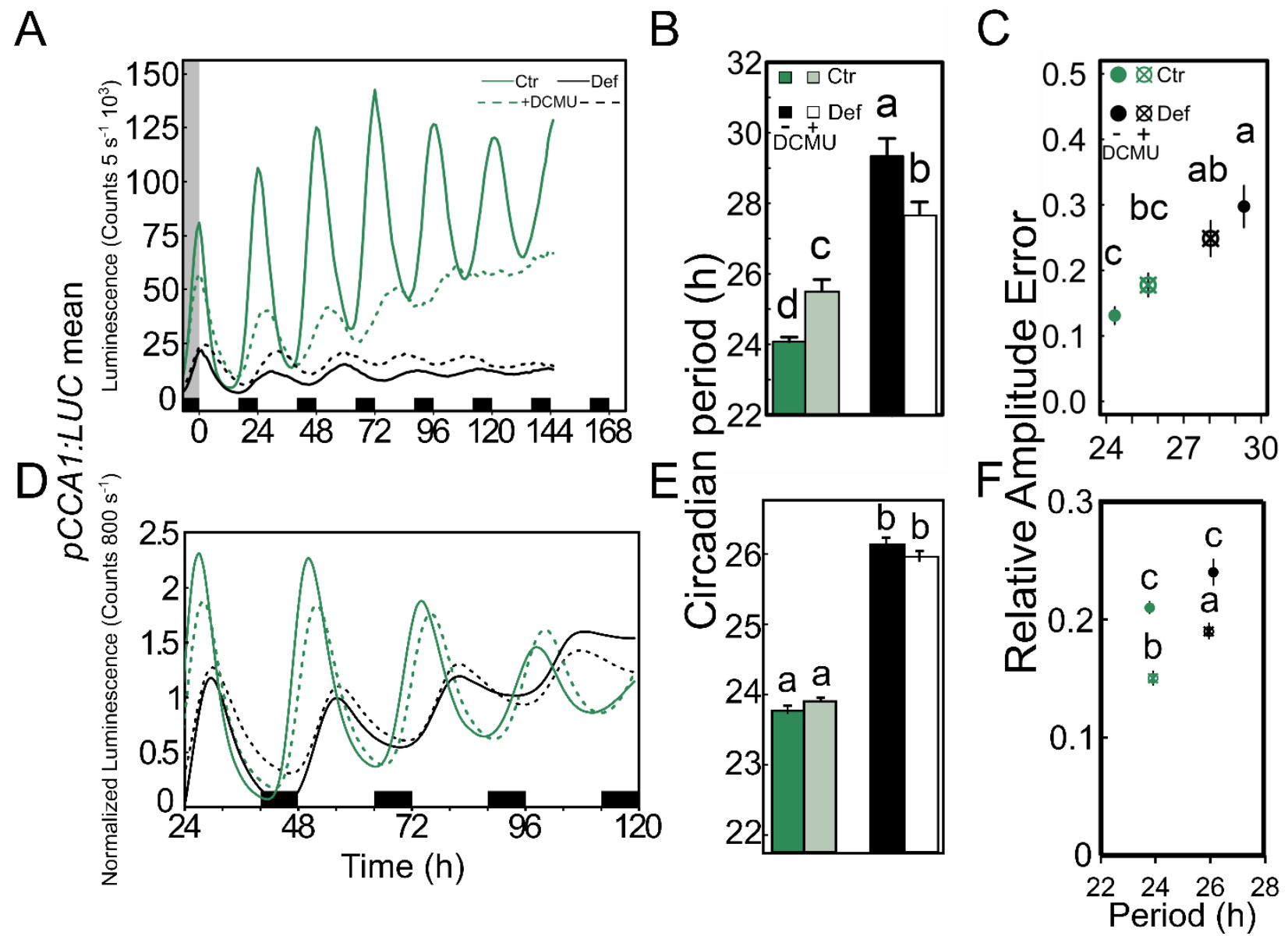
711 Fig. 6. Mg is not a zeitgeber to set circadian time. Seedlings were entrained for eight days to 712 12/12-h light/dark cycles on medium supplied with $50 \mu \mathrm{M} \mathrm{Mg}$ before released into LL. A pulse of $71310 \mathrm{mM} \mathrm{Mg}$ was applied during $4 \mathrm{~h}$ in $3 \mathrm{~h}$ intervals from ZT0 in LL along one circadian cycle. $(A)$ 714 Phase response of pCCA1:LUC activity rhythms to pulses of $\mathrm{Mg}$ at different time points in LL. 715 (B) RAE of the oscillations (mean \pm SEM, $n=6$ ). (C) RAE of pCCA1:LUC oscillations of 716 seedlings entrained on medium containing $5 \mu \mathrm{M} \mathrm{Mg}$ that were resupplied with $3 \mathrm{mM}$ Mg every 3 717 hours under LL conditions (means \pm SEM, $n=6$ ).
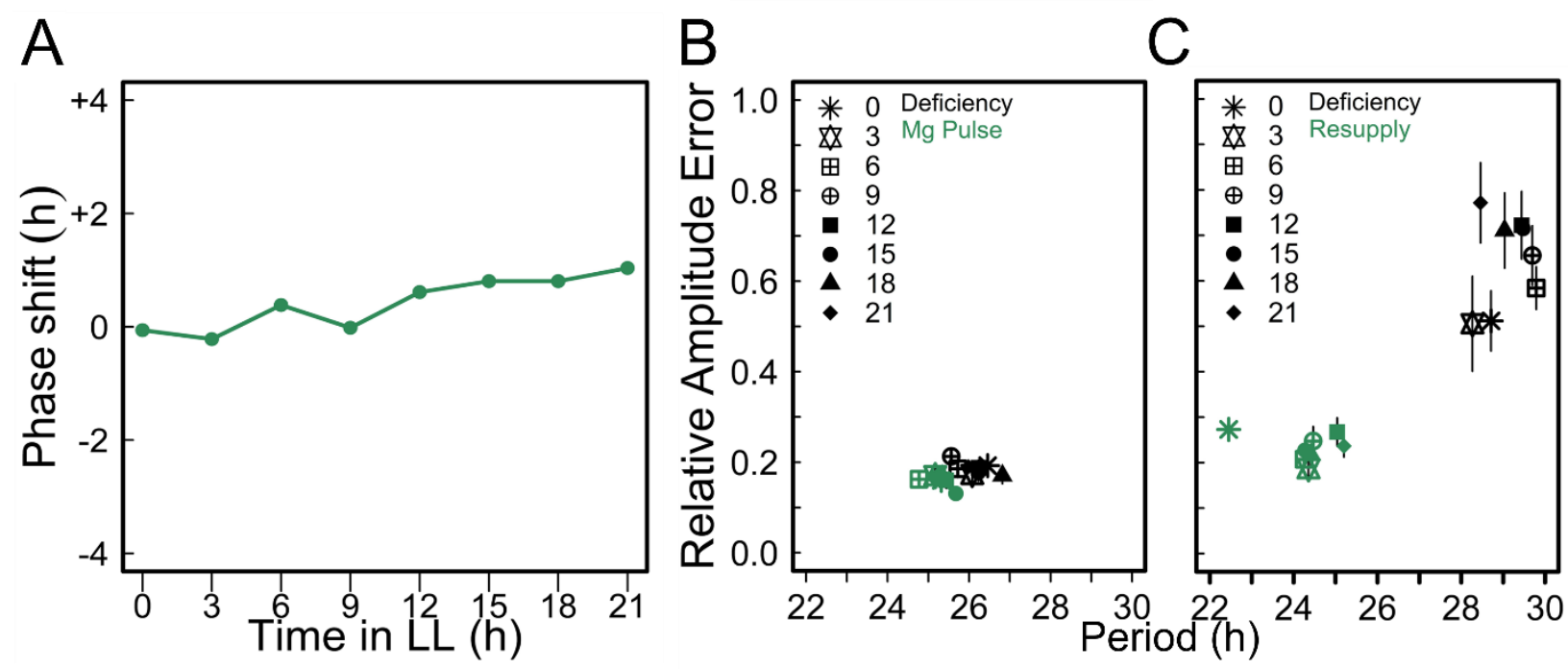
720 Fig. 7. Simulation of global effect of Mg deficiency on transcription/translation rate 721 increases the circadian period of CCA1 activity rhythms. $(A)$ CCA1/LHY oscillations under

$722 \mathrm{Mg}$ deficiency (blue) and when $\mathrm{Mg}$ was resupplied (red) under the assumption that $\mathrm{Mg}$ 723 deficiency affects global rates of transcription and translation. Vertical red bar represents the 724 time of simulated $\mathrm{Mg}$ resupply. (B) response curve to Mg pulse.

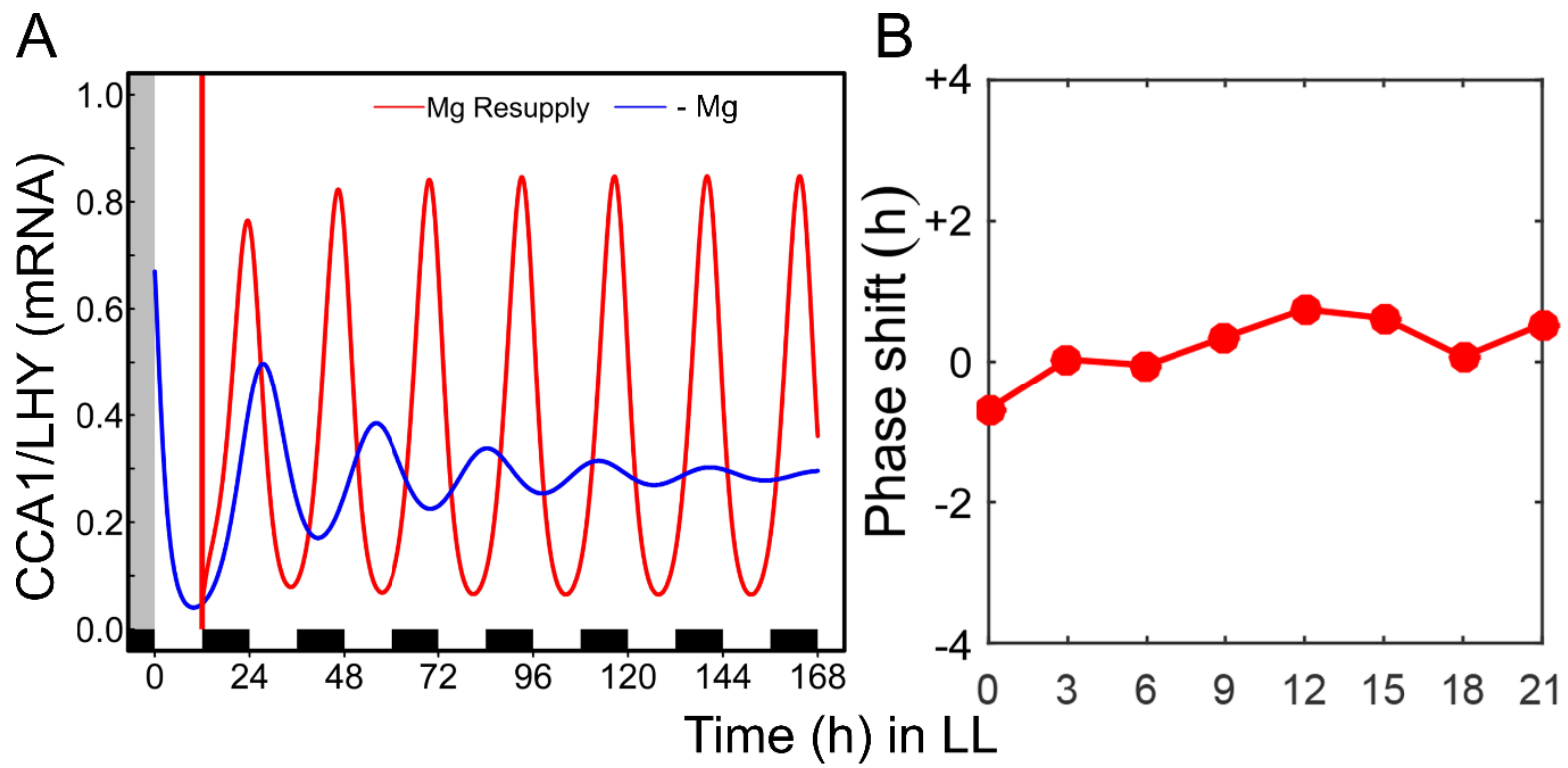


727 Fig. 8. Inhibiting translation increases circadian period of pCCA1:LUC. $p$ CCA1:LUC Col-0 728 seedlings were entrained for 11 days to 12 hour light/dark cycle on media supplied with different $729 \mathrm{Mg}$ concentrations before released into LL. Media were either without sucrose $(A-B)$ or 730 supplemented with $1 \%$ sucrose $(C-D) .0 .5 \mu \mathrm{g} \mathrm{mL}^{-1} \mathrm{CHX}(+\mathrm{CHX})$ or $0.1 \% \mathrm{DMSO}$ as control 731 (Ctr) were applied after 24 hours in LL. Estimated circadian period in hours (h) $(A, C)$ and 732 respective $\operatorname{RAE}(B, D)$ of $p C C A 1: L U C$ activity under LL after treatment. Significance was 733 determined by a Wilcoxon Rang Sum test. Different letters indicate significance at the level of $P$ $734 \leq 0.05$.

A

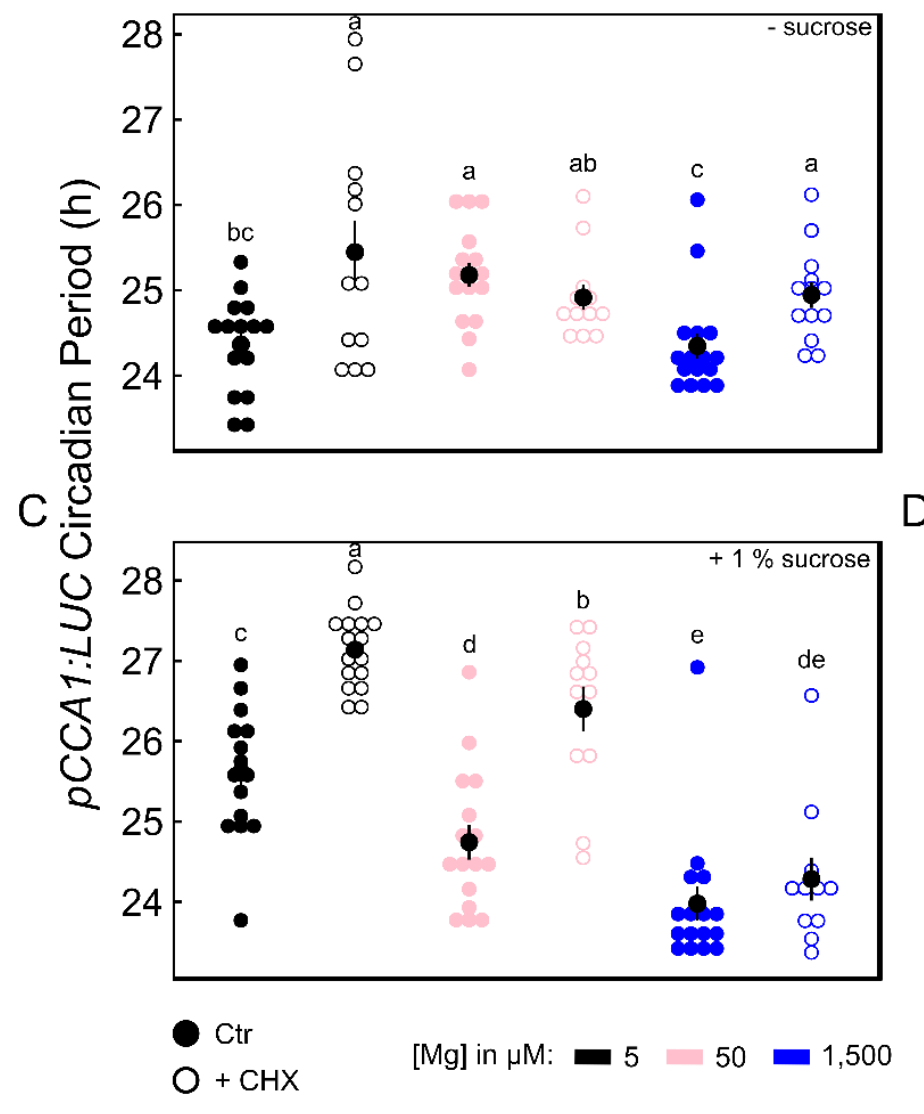

B

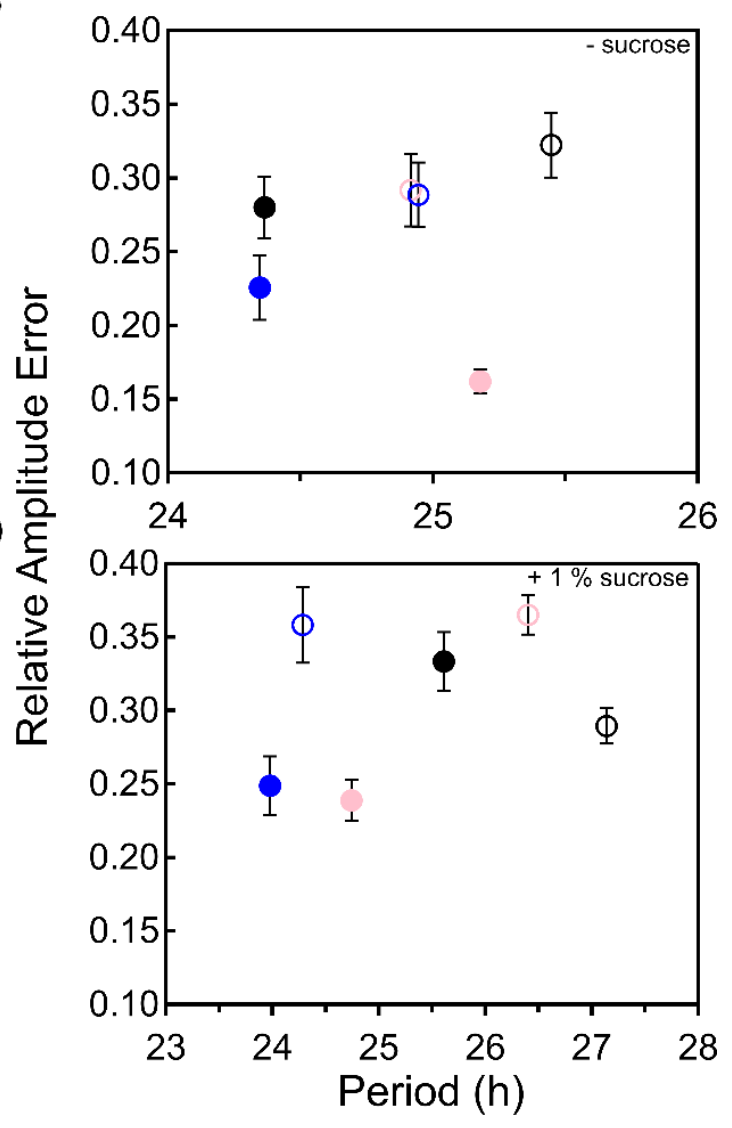




\section{SI Tables and Figures}

738 Table S1 Composition of modified MS medium for in vitro plant culture.

Salt

\begin{tabular}{|c|c|c|c|}
\hline Macronutrients & Sufficiency & Deficiency & \\
\hline $\mathrm{CaCl}_{2} \cdot 2 \mathrm{H}_{2} \mathrm{O}$ & \multicolumn{2}{|c|}{3.00} & $\mathrm{mmol} \mathrm{L}^{-1}$ \\
\hline $\mathrm{MgSO}_{4} \cdot 7 \mathrm{H}_{2} \mathrm{O}$ or $\mathrm{MgCl}_{2} \cdot 6 \mathrm{H}_{2} \mathrm{O}$ & 1.5 or 0.20 & 0.005 & $\mathrm{mmol} \mathrm{L}{ }^{-1}$ \\
\hline $\mathrm{KH}_{2} \mathrm{PO}_{4}$ & \multicolumn{2}{|c|}{1.25} & $\mathrm{mmol} \mathrm{L}^{-1}$ \\
\hline $\mathrm{KCl}$ & 1.00 & 1.195 & $\mathrm{mmol} \mathrm{L}^{-1}$ \\
\hline $\mathrm{KNO}_{3}$ & \multicolumn{2}{|c|}{6.00} & $\mathrm{mmol} \mathrm{L}^{-1}$ \\
\hline $\mathrm{Na}_{2} \mathrm{SO}_{4}$ & 0 & 1.495 or 0.195 & $\mathrm{mmol} \mathrm{L}^{-1}$ \\
\hline \multicolumn{4}{|l|}{ Micronutrients } \\
\hline $\mathrm{KI}$ & \multicolumn{2}{|c|}{5.0} & $\mu \mathrm{mol} \mathrm{L} \mathrm{L}^{-1}$ \\
\hline $\mathrm{H}_{3} \mathrm{BO}_{3}$ & \multicolumn{2}{|c|}{100} & $\mu \mathrm{mol} \mathrm{L} \mathrm{L}^{-1}$ \\
\hline $\mathrm{MnSO}_{4}$ & \multicolumn{2}{|c|}{132} & $\mu \mathrm{mol} \mathrm{L} \mathrm{L}^{-1}$ \\
\hline $\mathrm{ZnSO}_{4}$ & \multicolumn{2}{|c|}{30} & $\mu \mathrm{mol} \mathrm{L} \mathrm{L}^{-1}$ \\
\hline $\mathrm{CuSO}_{4}$ & \multicolumn{2}{|c|}{0.1} & $\mu \mathrm{mol} \mathrm{L} \mathrm{L}^{-1}$ \\
\hline $\mathrm{Co}_{2} \mathrm{Cl}$ & \multicolumn{2}{|c|}{0.1} & $\mu \mathrm{mol} \mathrm{L} \mathrm{L}^{-1}$ \\
\hline $\mathrm{Na}_{2} \mathrm{MoO}_{4}$ & \multicolumn{2}{|c|}{1.0} & $\mu \mathrm{mol} \mathrm{L} \mathrm{L}^{-1}$ \\
\hline Fe-EDTA & \multicolumn{2}{|c|}{100} & $\mu \mathrm{mol} \mathrm{L} \mathrm{L}^{-1}$ \\
\hline Sucrose & \multicolumn{2}{|c|}{30} & $\mathrm{mmol} \mathrm{L}^{-1}$ \\
\hline MES-KOH pH 5.7 & \multicolumn{2}{|c|}{2.56} & $\mathrm{mmol} \mathrm{L}^{-1}$ \\
\hline Plant Agar (Mg-free)* & \multicolumn{2}{|c|}{0.5} & $\%$ \\
\hline
\end{tabular}


742 Table S2 List of primers used for quantification of transcript levels.

\begin{tabular}{|c|c|c|c|}
\hline Primer name & Sequence (5'-3') & Efficiency & Source \\
\hline $\begin{array}{l}\overline{\text { Fw } C D K A} \\
\operatorname{Rv} C D K A\end{array}$ & $\begin{array}{l}\text { attgcgtattgccactctcatagg } \\
\text { tcctgacagggataccgaatgc }\end{array}$ & 1.98 & $\begin{array}{c}\text { (Hermans et al., } \\
\text { 2010a) }\end{array}$ \\
\hline 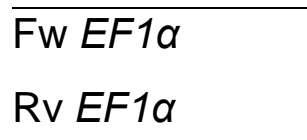 & $\begin{array}{l}\text { tgagcacgctcttcttgctttca } \\
\text { ggtggtggcatccatcttgttaca }\end{array}$ & 1.97 & $\begin{array}{l}\text { (Becher et al., } \\
\text { 2004) }\end{array}$ \\
\hline $\begin{array}{l}\text { Fw UBQ10 } \\
\text { Rv UBQ10 }\end{array}$ & $\begin{array}{l}\text { ggccttgtataatccctgatgaataag } \\
\text { aaagagataacaggaacggaaacatagt }\end{array}$ & 1.93 & This study \\
\hline $\begin{array}{l}\text { Fw CCA1 } \\
\text { Rv CCA1 }\end{array}$ & $\begin{array}{l}\text { cacgctcagaaattttctccaagg } \\
\text { acacccgttttgacataaggatcg }\end{array}$ & 1.95 & $\begin{array}{l}\text { (Hermans et al., } \\
\text { 2010a) }\end{array}$ \\
\hline $\begin{array}{l}\text { Fw } C A X 3 \\
\text { Rv } C A X 3\end{array}$ & $\begin{array}{l}\text { acgtgggacttcaacccatg } \\
\text { tccctctgacaaagtctctc }\end{array}$ & 1.99 & $\begin{array}{c}\text { (Kamiya et al., } \\
\text { 2012) }\end{array}$ \\
\hline
\end{tabular}



seedlings. Estimated circadian period in hours (h) under continuous light from different Col-0 LUC report lines of the central oscillator (mean \pm SEM, $n=20$ ). Seedlings were entrained for 11 days to 12 hour light/dark cycle on media supplied with different $\mathrm{Mg}$ concentrations and released into continuous light. Media were either supplemented with $1 \%$ sucrose $(A-C)$ or without sucrose (D-F). (A, D) pCCA1:LUC, (B, E) pPRR7:LUC, (C, F) pTOC1:LUC. Significance was determined by a Wilcoxon Rang Sum test. Different letters indicate significance at the level

752 of $P \leq 0.05$. Experiments were undertaken indepently in laboratories of Cambridge University in 753 oder to repeat results obtained at Université libre de Bruxelles (Fig. 1) and to complement those 754 data using different reporter genes of the circadian oscillator.

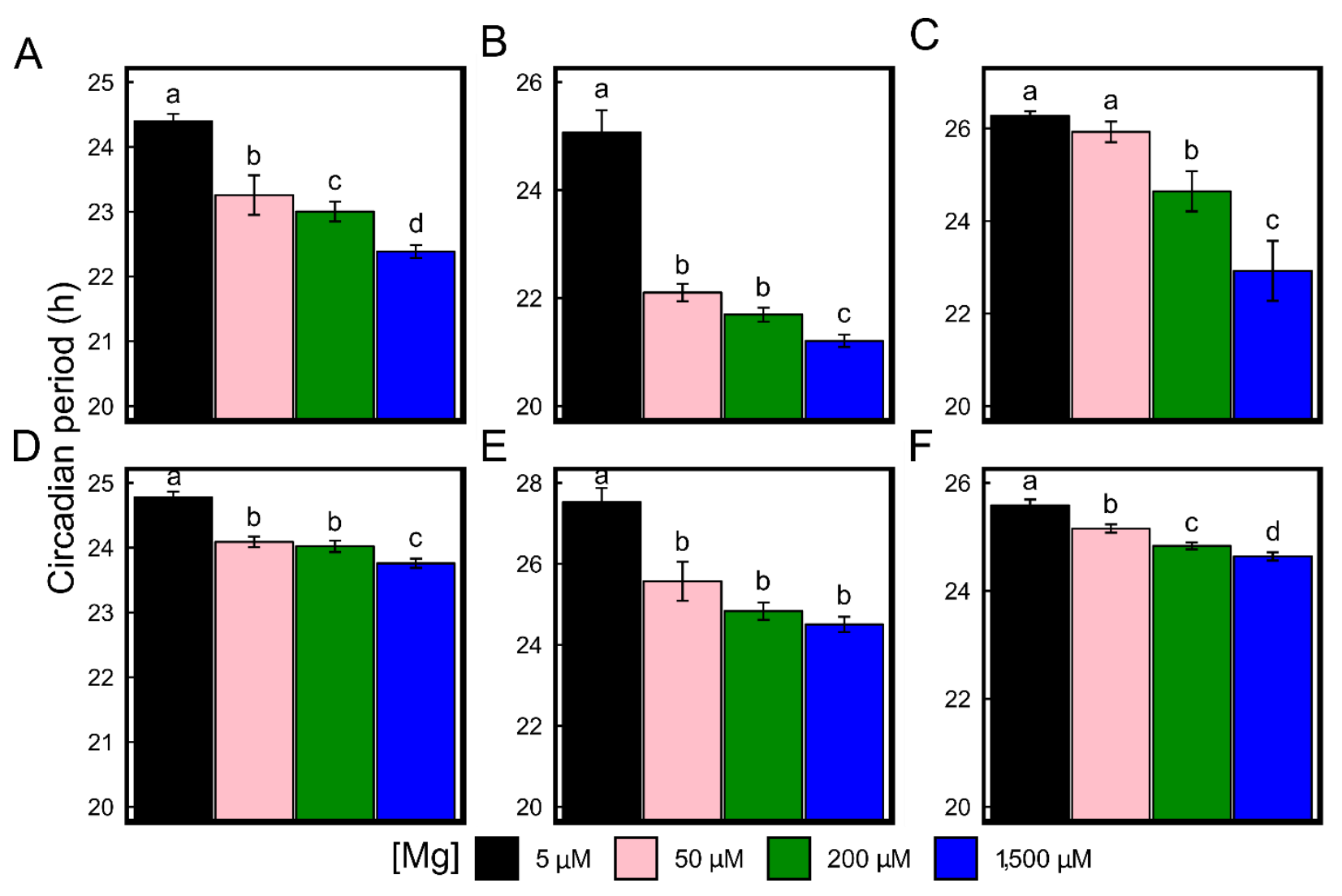


Fig. S2. Limited external $\mathbf{N}$ availability does not alter the circadian period. Seedlings entrained for eight days to 12/12-h light/dark cycles on either control (N [10 mM] supplied as $\mathrm{KNO}_{3}$ ) or $\mathrm{N}$-deficient $\left(\mathrm{N}[0.01 \mathrm{mM}]\right.$; $\mathrm{K}^{+}$shortage was compensated by $\left.9.99 \mathrm{mM} \mathrm{KCl}\right)$ media were released into continuous light. $(A)$ luminescence traces of $p C C A 1: L U C$ activity $(B)$ estimated circadian period of $p C C A 1: L U C$ oscillations under $L L,(C)$ circadian phase of $p C C A 1: L U C$ peak expression, $(D)$ relative amplitude error of the oscillations (mean \pm SEM, $n=48),(E$ ) morphological phenotype of seedlings after 7 days in continuous light. Statistically significance was verified by Two-Sample Student's $t$-test with a 95\% confidence interval. Asterisks represent significance at ${ }^{* \star *} P<0.001$ ).
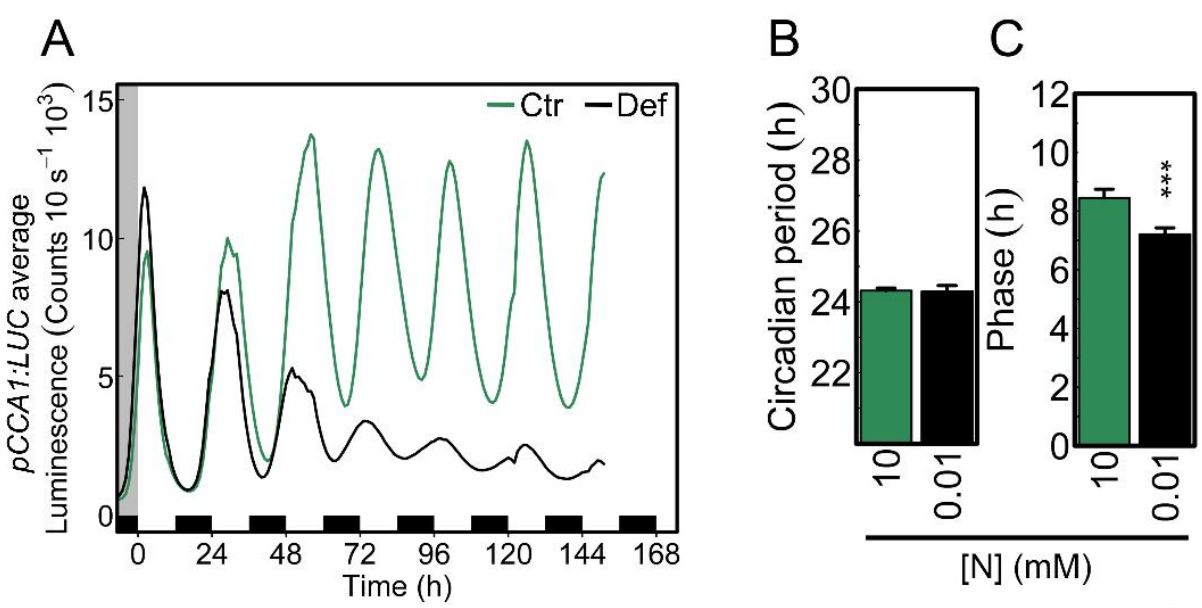

$[\mathrm{N}](\mathrm{mM})$
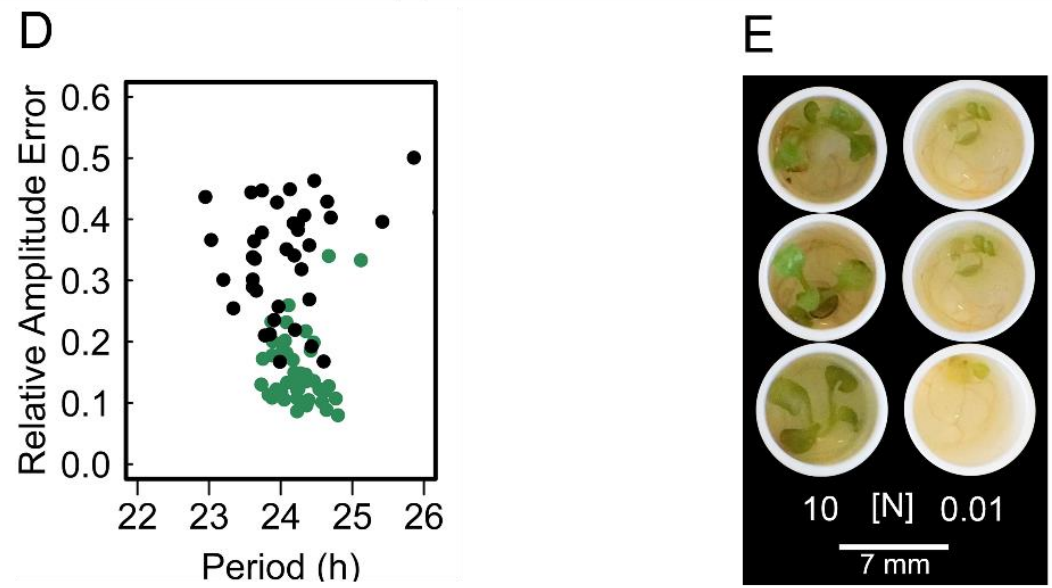
768 Fig. S3. Mg deficiency does not alter the circadian period of PRR7:LUC activity under

769 light/dark conditions. Arabidopsis seedlings were entrained for 11 days to $12 / 12$ hour 770 light/dark cycle on media supplied with different $\mathrm{Mg}$ concentrations and circadian period of 771 pPRR7:LUC activity was estimated over a course of four days under entrainment conditions. $(A)$ 772 absence of sucrose, $(B)$ presence of $1 \%$ sucrose.

A

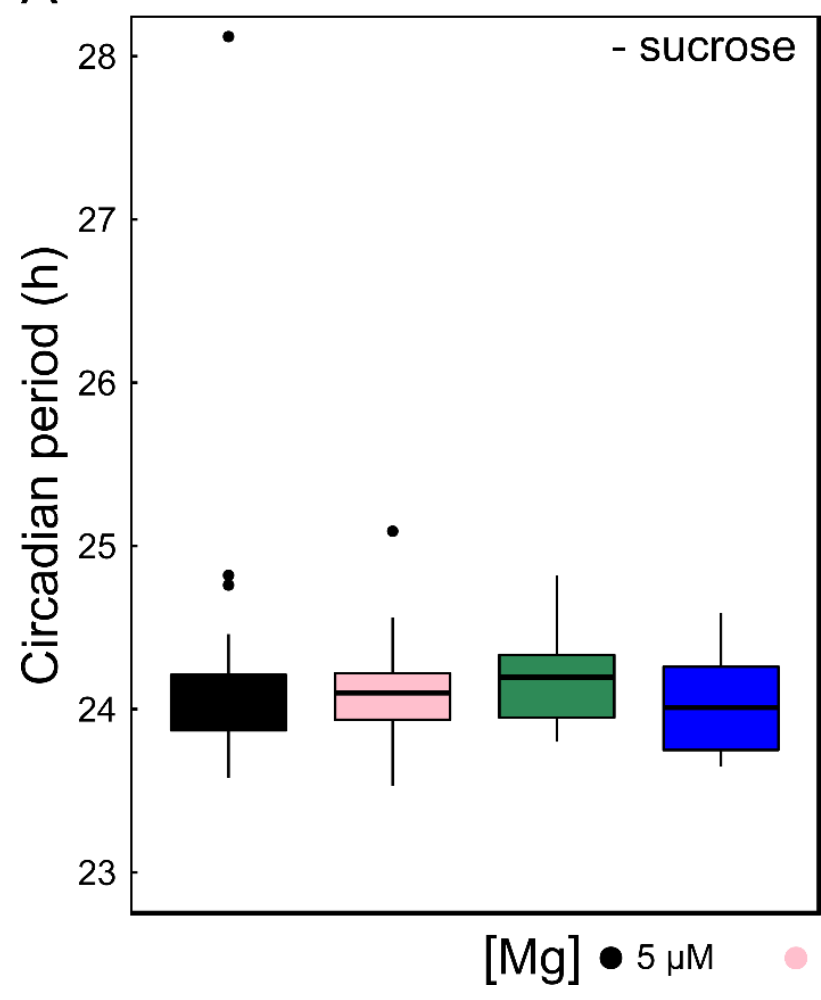

B

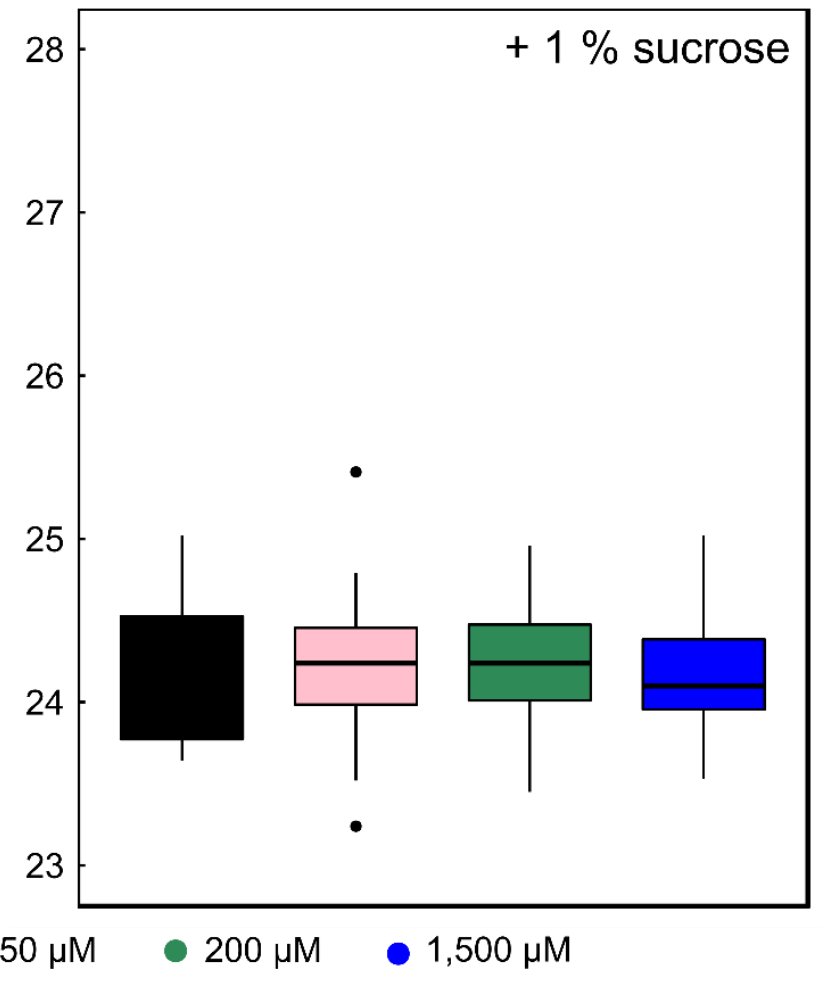


Fig. S4. Young Arabidopsis seedlings successfully cope with lower Mg concentrations than the usually supplied in the growth medium. $(A)$ Experimental design for seedlings

777 entrained for eight days to $12 / 12$-h light/dark cycles on either $1,500 \mu \mathrm{M}$ or $200 \mu \mathrm{M} \mathrm{Mg}$ media

778 and thereafter released into continuous light with either fully supplied $\mathrm{Mg}$ or $\mathrm{Mg}$-deficient media

779 to assess $(B)$ morphological phenotype, $(C)$ fresh biomass [mean \pm SEM, $n=4(1=20$ pooled

780 seedlings)], (D) mRNA levels of $C A X 3$. Statistically significance was verified by One-Way

781 ANOVA followed by Tukey HSD post-hoc test $(P<0.001)$.

A

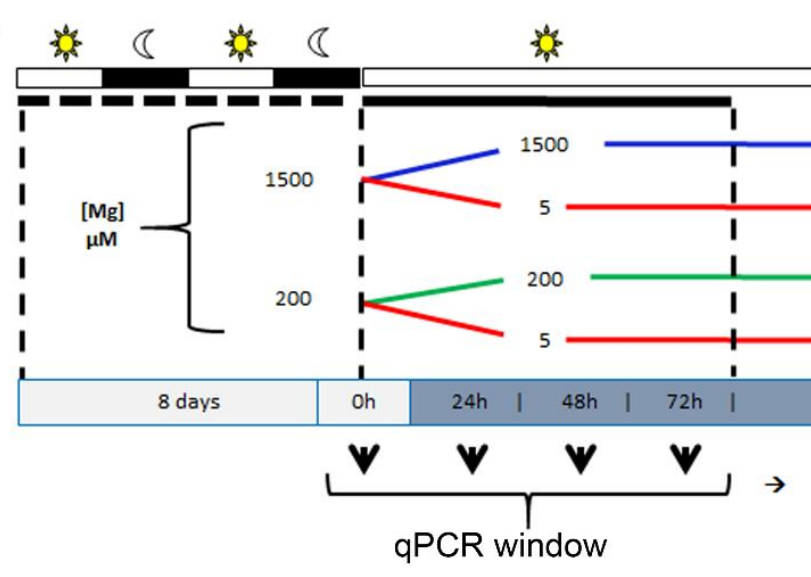

$\mathrm{D}$

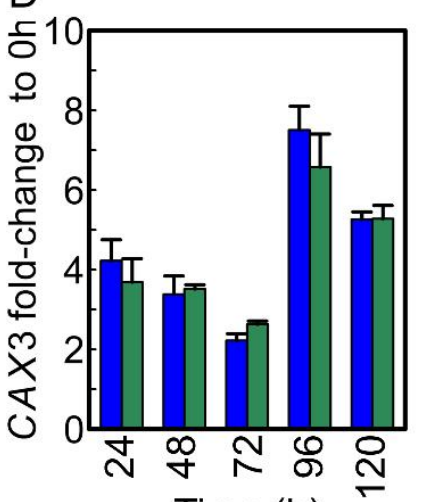

Time (h)
C

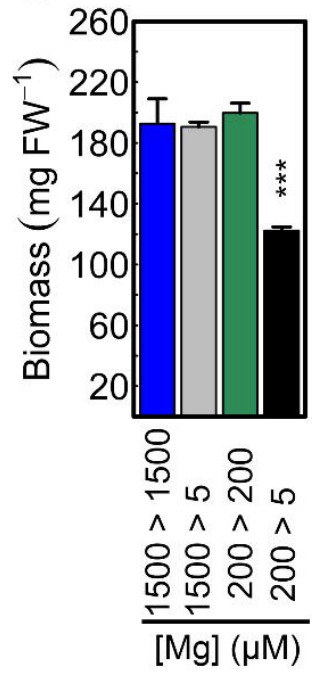


Fig. S5. DCMU treatment without external supply of sucrose hampers circadian oscillations of pCCA1:LUC. Normalized mean luminescence traces of pCCA1:LUC in LL conditions after seedlings were entrained for 11 days to 16/8-h light/dark cycles on either 200 $\mu \mathrm{M}$ (Ctr) or $5 \mu \mathrm{M} \mathrm{Mg}$ (Def) without external supply of sucrose. Seedlings were transferred to

787 respective medium containing $20 \mu \mathrm{M}$ DCMU prior to release into LL.

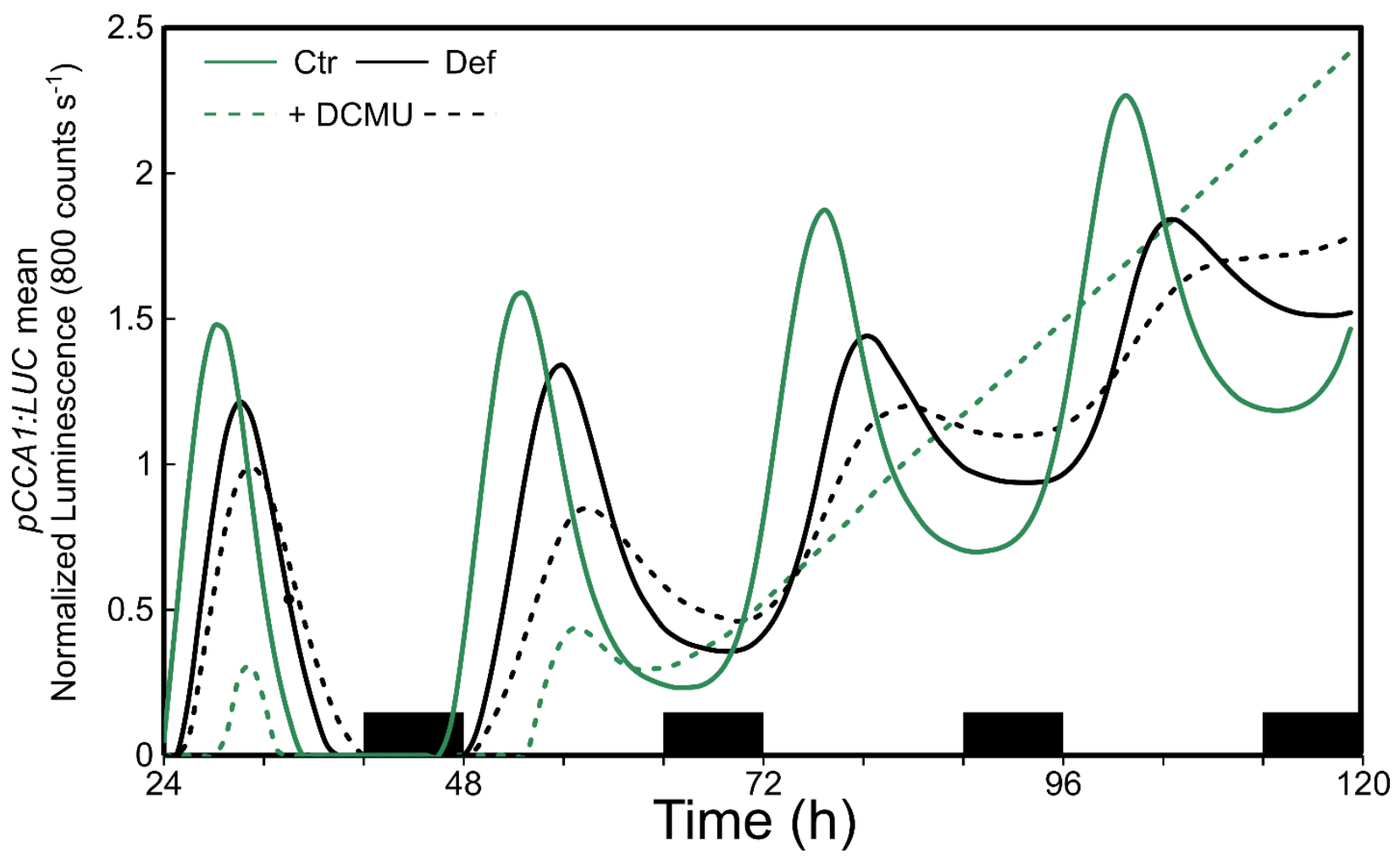


Fig. S6. Excess Mg supply maintains the circadian period in Arabidopsis thaliana seedlings. Estimated circadian period in hours $(h)$ under LL from pCCA1:LUC reporter line

792 (mean \pm SEM, $n=20$ ). Seedlings were entrained for 11 days to 12/12 hour light/dark cycle on 793 media supplied with different Mg concentrations before released into LL. Media were either 794 supplemented with $1 \%$ sucrose $(A)$ or without sucrose $(B)$. Significance was determined by a 795 Wilcoxon Rang Sum test. Different letters indicate significance at the level of $P \leq 0.05$.
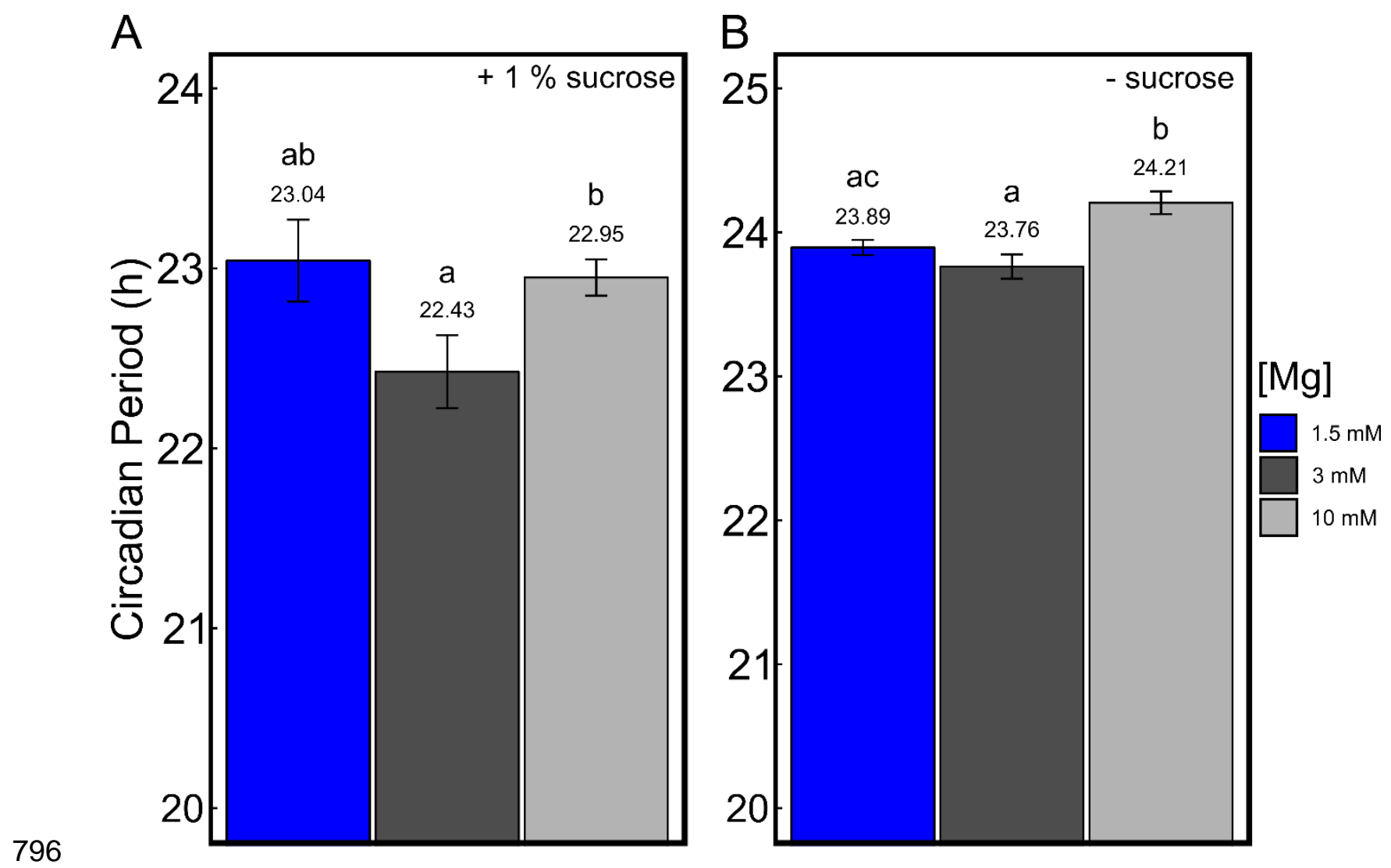
798 Fig. S7. Modelling predictions and translation inhibition assay. Simulations of the 799 behaviour of wild type Arabidopsis circadian clock under free running conditions in LL when 800 single parameters are changed. $(A)$ reduced PRR5/TOC1 protein degradation, $(B)$ reduced 801 PRR7/PRR9 RNA synthesis, $(C)$ reduced RNA synthesis of the ELF4/LUX evening complex.

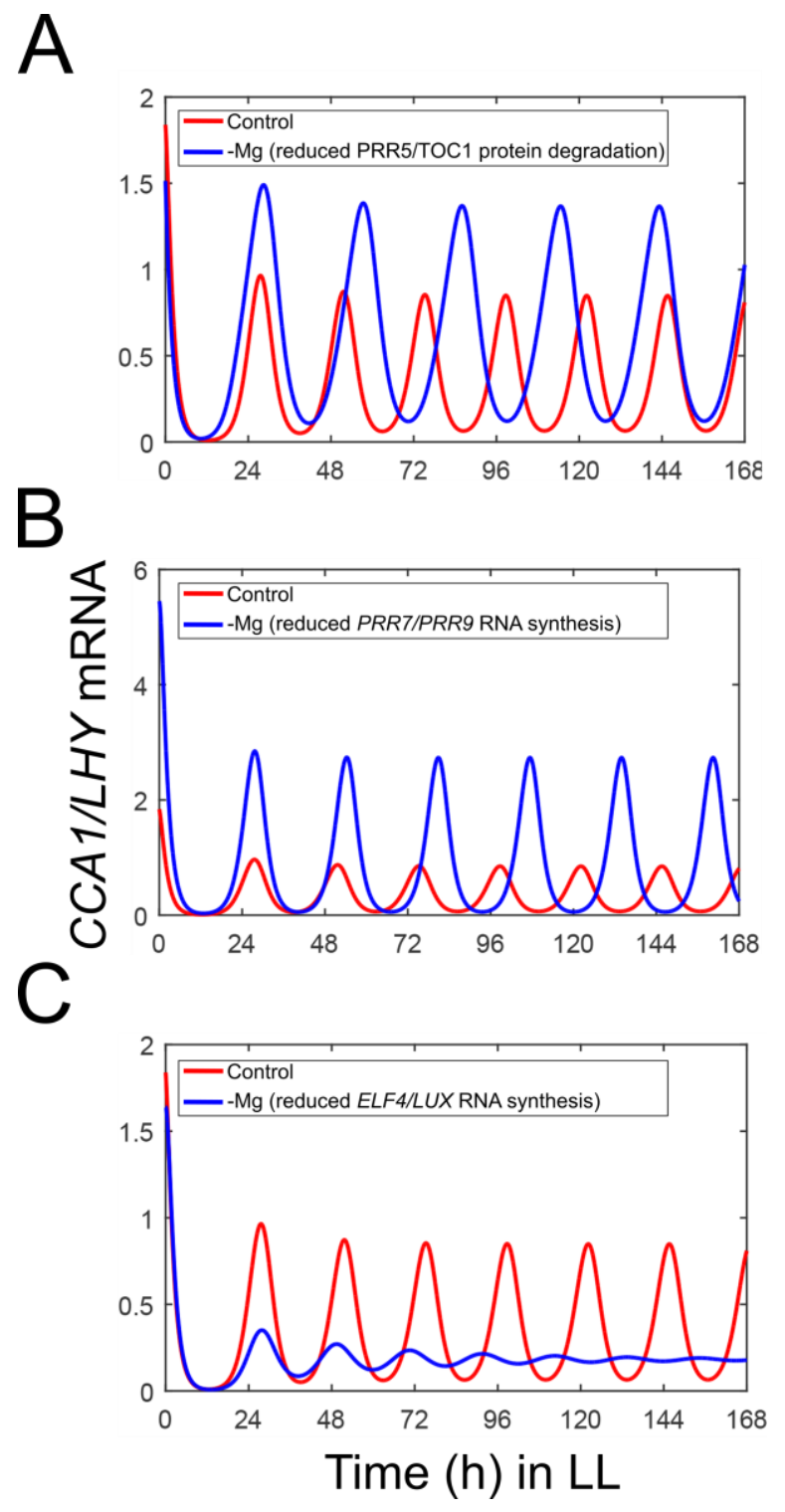

803 
804 Fig. S8. Adding $\mathrm{MgCl}_{2}$ as external $\mathrm{Mg}$ source increased the circadian period of 805 pCCA1:LUC. Arabidopsis seedlings were entrained for eight days to 12/12 hour light/dark 806 cycles on media supplied with the referred $\mathrm{Mg}$ concentrations before released into LL. $(A)$ 807 average luminescence traces of pCCA1:LUC activity, $(B)$ estimates circadian period (h) of 808 pCCA1:LUC activity (mean \pm SEM, $n=24$ ) and correlation between circadian period vs. 809 external Mg concentrations. Significance was verified by Two-Sample Student's $t$-test $95 \%$ 810 confidence interval, One-Way ANOVA followed by Tukey HSD post-hoc test and Pearson's rho 811 correlation coefficient. Different letters indicate significance at the level of $P<0.05$.
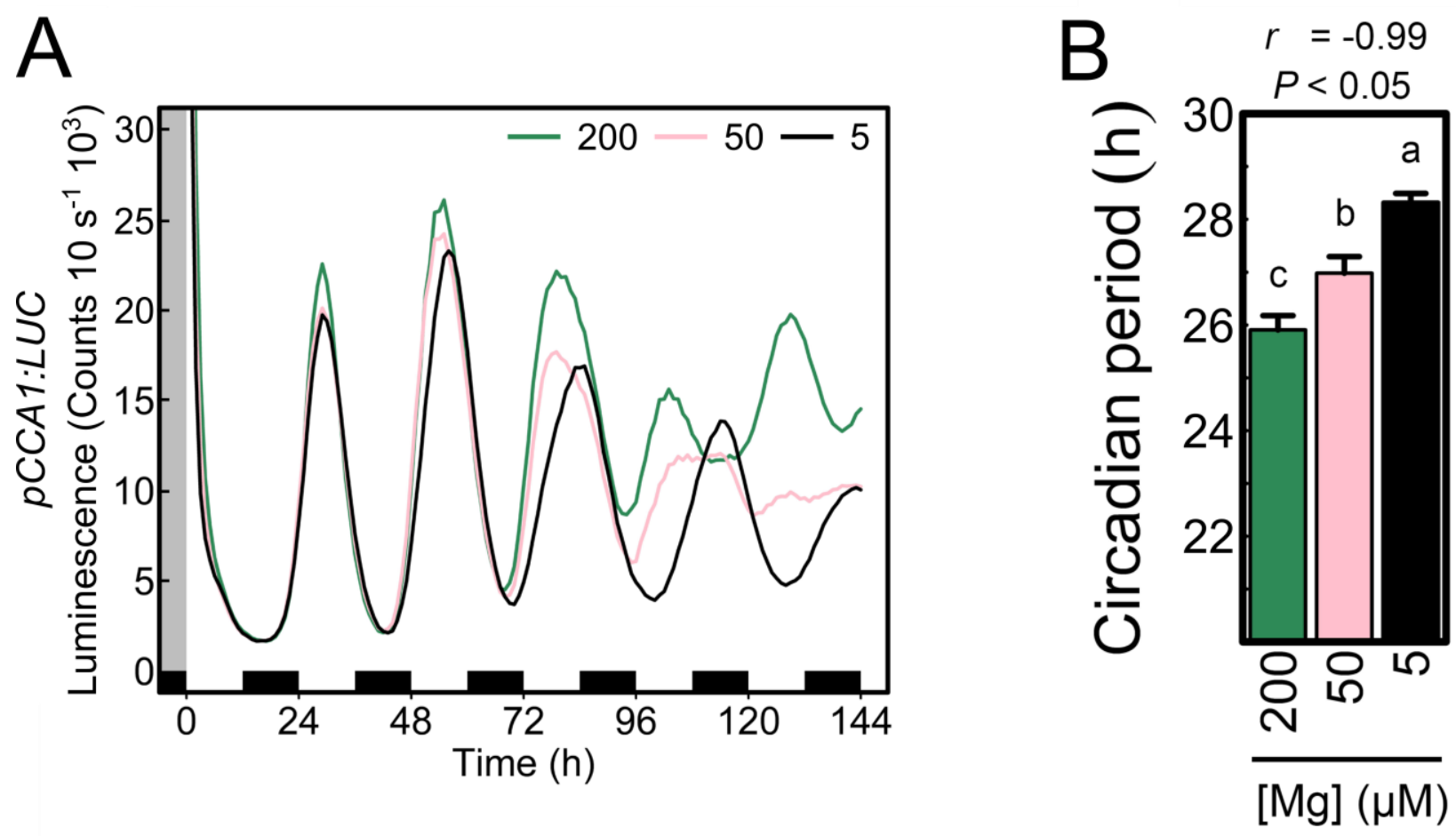

812 
814 Fig. S9. Experimental design of $(A) M g$ resupply and $(B)$ phase response curve.

A

$\underset{\text { Start of LL }}{\rightarrow} \mathrm{MS}+1 \%$ sucrose, $100 \mu \mathrm{E}$ in LL $\downarrow$ 12:12L0 -

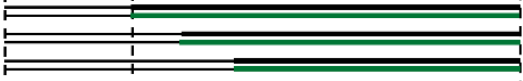

$5 \mu \mathrm{m}$
$\equiv$

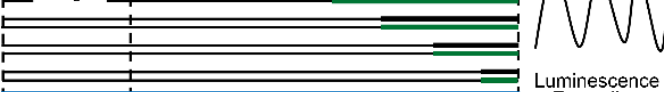

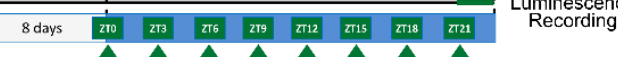

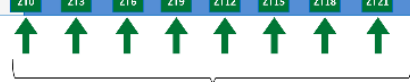

Mg Resupply

$5 \mu \mathrm{M} \mathrm{Mg}$ (Control) or $3 \mathrm{mM} \mathrm{Mg}$

Day $9-16$
B $\rightarrow$ MS $+1 \%$ sucrose, $100 \mu \mathrm{E}$ in LL

Start of $\mathrm{LL} \quad$ Day 8

Day $9-16$

12:12 LD -

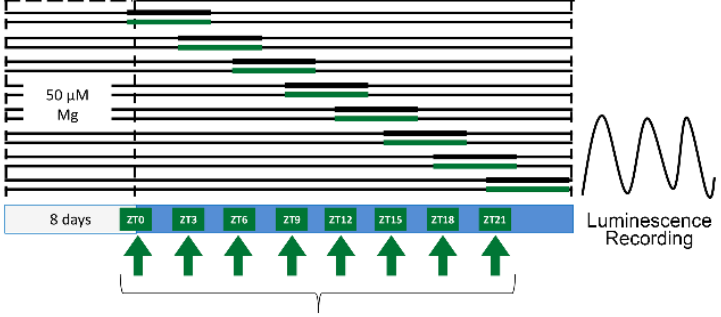

Mg Pulse (during 4h)

$50 \mu \mathrm{M} \mathrm{Mg}$ (Control) or $10 \mathrm{mM} \mathrm{Mg}$ 
Fig. 1. Limiting external Mg availability alters circadian oscillations of CCA1:LUC. $(A)$ Mean circadian oscillations of pCCA1:LUC in LL conditions after being entrained to 12/12-h light/dark cycles for eight days on media supplied with different Mg concentrations. $(B)$ pCCA1:LUC period estimates in $\mathrm{h}$ under $\mathrm{LL}$. (C) relative amplitude error of oscillations (mean \pm SEM, $n=12$ ) of $p C C A 1: L U C$. $(D)$ Fresh biomass and $(E)$ morphological phenotype of seedlings at the end of the experiment. $(F)$ dry biomass and $(G) \mathrm{Mg}$ concentration in plant tissue [mean \pm SEM, $n=3(1=15$ pooled seedlings)] of 12-day-old seedlings cultivated in light/dark cycles on control (Ctr.: $200 \mu \mathrm{M} \mathrm{Mg}$ ) and deficient media (Def.: $5 \mu \mathrm{M} \mathrm{Mg}$ ). Significance was verified by $(B)$ Spearman's rho correlation coefficient and Kruskal-Wallis Rank Sum Test followed by Nemenyi post-hoc test, $(C)$ One-Way ANOVA followed by Tukey HSD post-hoc test and ( $F-G)$ Two-Sample Student's $t$-test 95\% C.I. (different letters indicate significance at the level of $P<0.05$. Asterisks represent significance at ${ }^{*} P<0.05$, ${ }^{* *} P<$ 0.01 , and ${ }^{* \star *} P<0.001$ ).
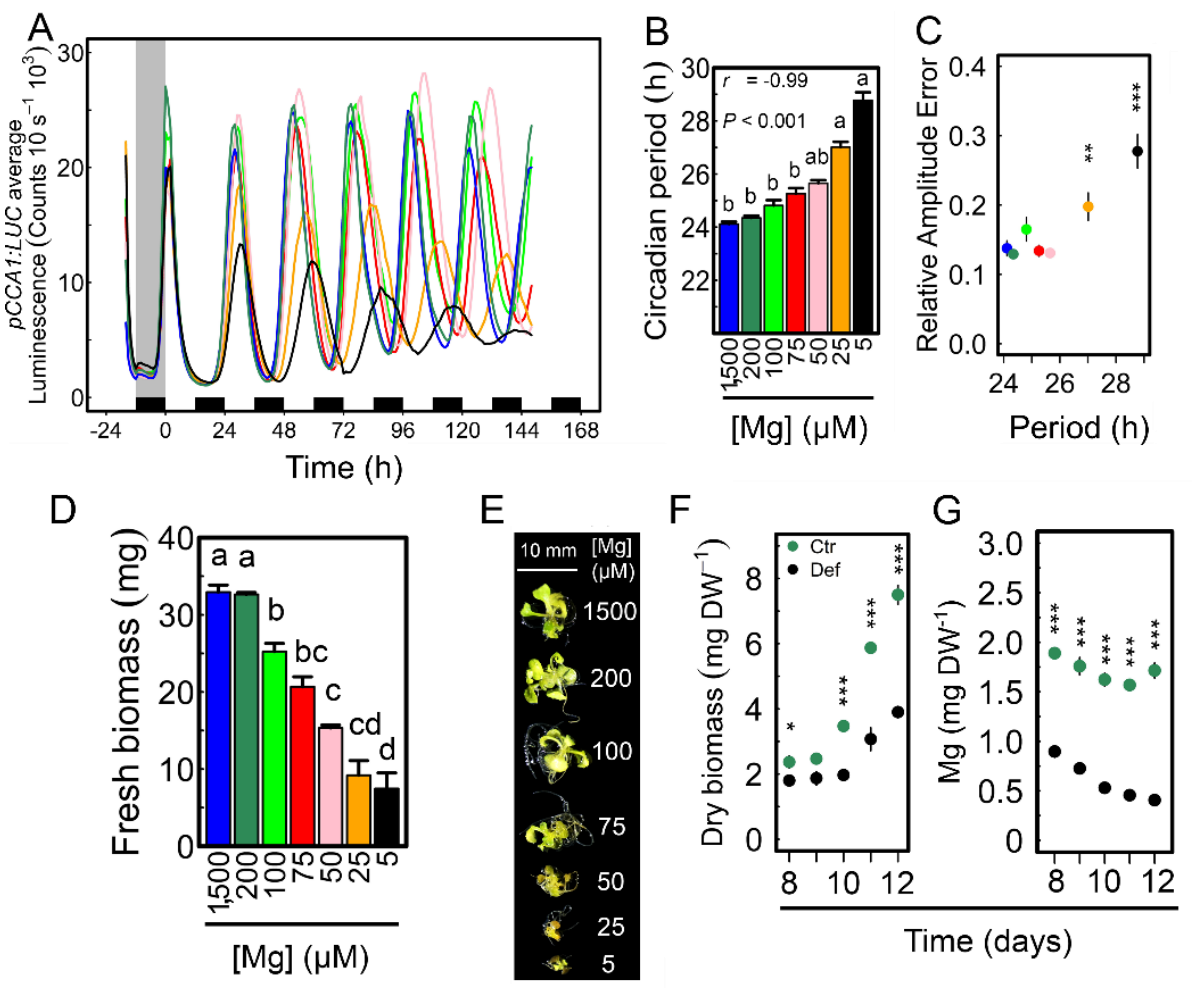
bioRxiv preprint doi: https://doi.org/10.1101/2020.05.14.096537; this version posted May 19, 2020. The copyright holder for this preprint (which was not certified by peer review) is the author/funder. All rights reserved. No reuse allowed without permission.

Fig. 2. Mg deficiency delays the circadian phase of PRR7. $(A)$ Circadian phase of peak expression (mean \pm SEM) in 12/12 hour light/dark cycle of pCCA1:LUC, pPRR7:LUC and pTOC1:LUC in 11-day-old Col-0 WT Arabidopsis seedlings $(\mathrm{n}=20)$ in the absence or presence of $1 \%$ sucrose. Circadian phase of $p P R R 7: L U C$ peak expression in a four day 12/12 hour light/dark cycle under different Mg supply in the $(B)$ absence or $(C)$ presence of 1 $\%$ sucrose. Significance was determined by a Wilcoxon Rang Sum test. Different letters indicate significance at the level of $P \leq 0.05$.

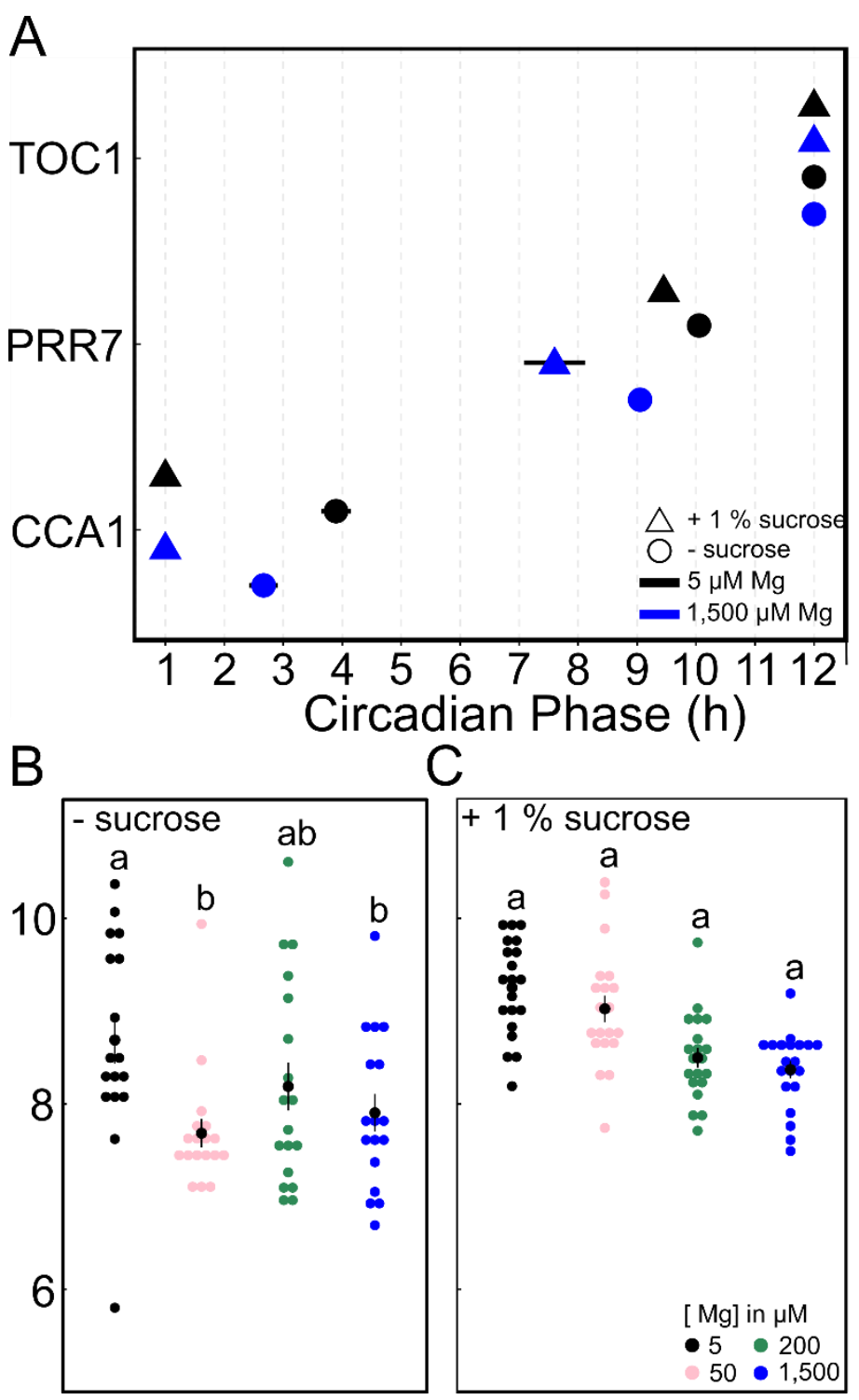


bioRxiv preprint doi: https://doi.org/10.1101/2020.05.14.096537; this version posted May 19, 2020. The copyright holder for this preprint (which was not certified by peer review) is the author/funder. All rights reserved. No reuse allowed without permission.

Fig. 3. Oscillator alteration occurs concomitantly with expression of the Mg deficiency

marker CAX3. Seedlings entrained for eight days to 12/12-h light/dark cycles on medium with 200 or $1,500 \mu \mathrm{M} \mathrm{Mg}$ were transferred to fresh media either deficient in $\mathrm{Mg}(5 \mu \mathrm{M})$ or fully supplied and released in continuous light. $(A)$ CAX3 mRNA expression [mean \pm SEM, $n$ $=3(1=30$ pooled seedlings $)]$ after transfer from 1,500 $\mu \mathrm{M} \mathrm{Mg},(\mathrm{B}-\mathrm{C})$ CAX3 mRNA expression and CCA1 mRNA expression [mean \pm SEM, $n=3(1=30$ pooled seedlings)] after transfer from $200 \mu \mathrm{M} \mathrm{Mg,}(D)$ correlation between estimated circadian period and external $\mathrm{Mg}$ concentration, $(E)$ average luminescence traces of $p C C A 1: L U C$ activity. Significance was verified by Pearson's Product Moment correlation coefficient $(P<0.01)$ and One-Way ANOVA followed by Tukey HSD post-hoc or Two-Sample Student's $t$-test at a 95\% confidence interval (asterisks represent significance at ${ }^{*} P<0.05$, ${ }^{* *} P<0.01$, and ${ }^{* * *} P<$ $0.001)$.

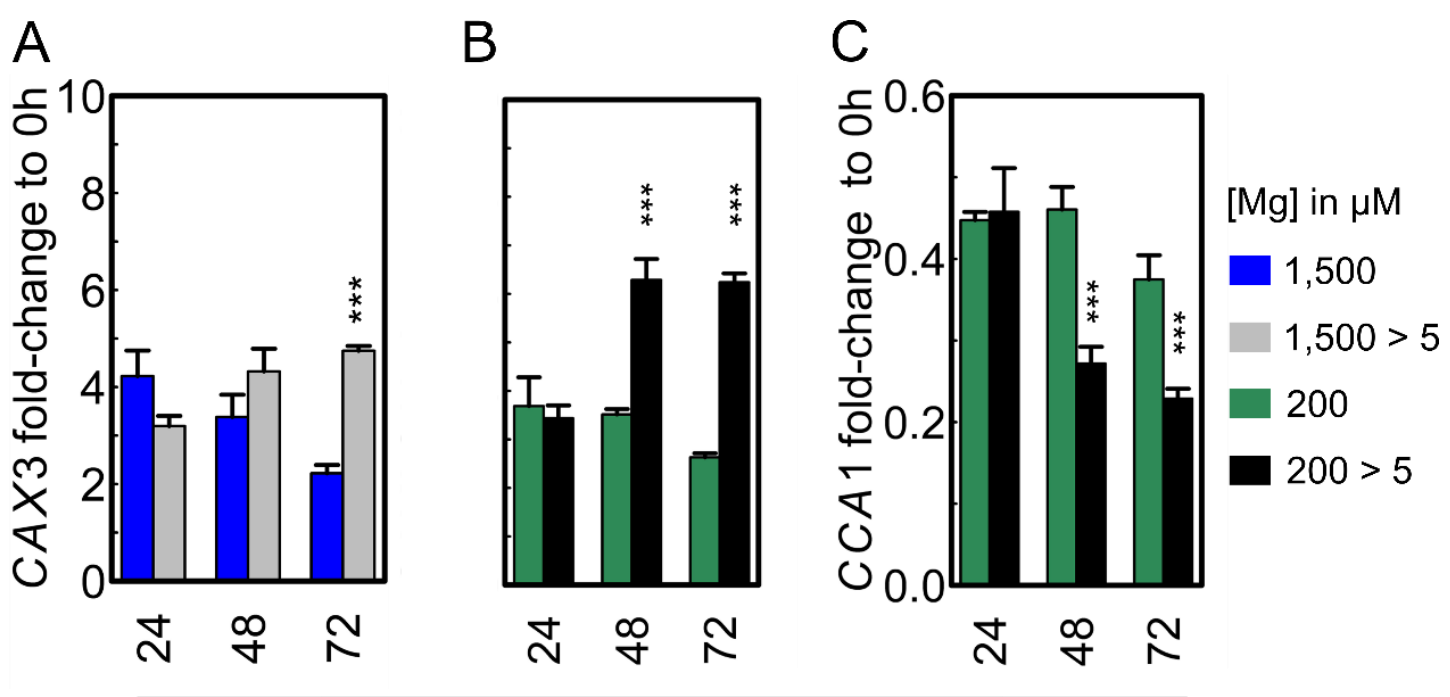

Time since Mg removal $(\mathrm{h})$

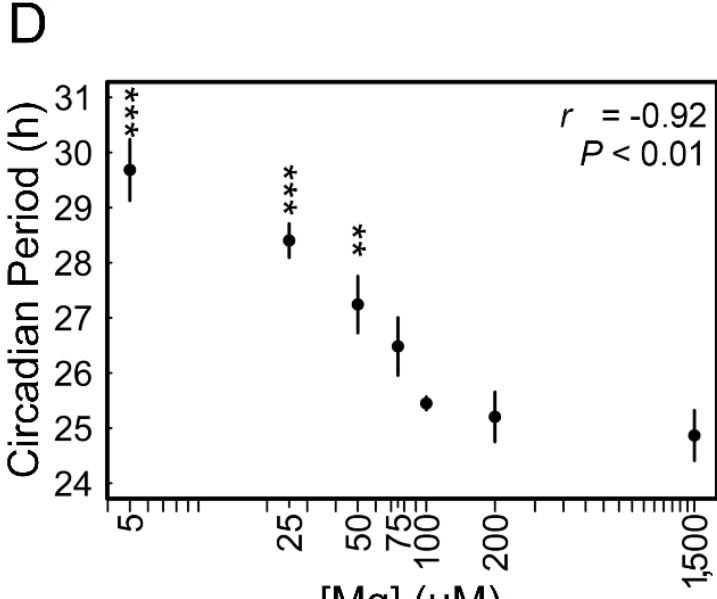

$[\mathrm{Mg}](\mu \mathrm{M})$

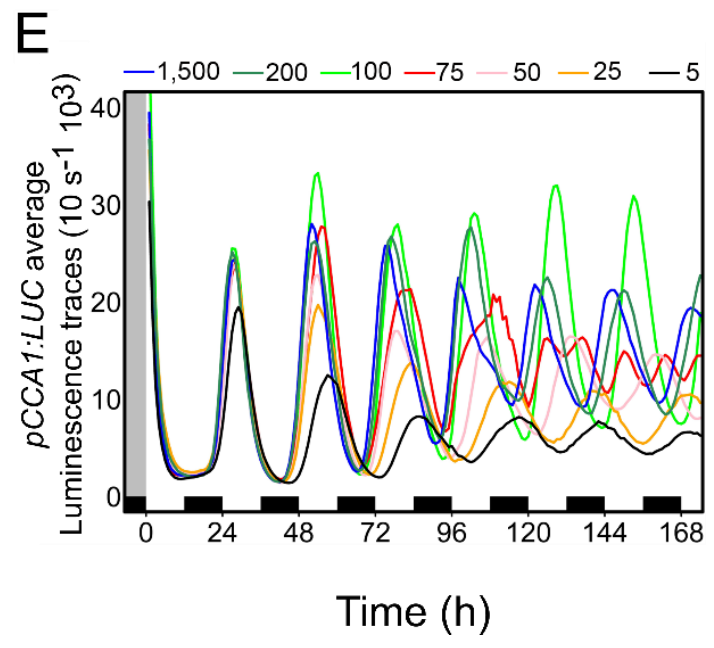


Fig. 4. Increase of circadian period due to Mg deficiency is light dependent. $(A)$ fresh weight (FW) biomass (mean \pm SEM, $n=3-4$ [1 = 4 pooled seedlings]) of seedlings entrained to long day (LD) 16/8 light/dark cycles and short day (SD) $8 / 16 \mathrm{~h}$ light/dark cycles. pCCA1:LUC average luminescence traces of seedlings entrained for eight days to $(B) L D$, (C) SD on Mg sufficient (Ctr.: $200 \mu \mathrm{M})$ and deficient (Def.: $5 \mu \mathrm{M}$ ) media before released into $\mathrm{LL},(D)$ relative amplitude error of LD and SD (mean \pm SEM, $n=12-48$ ). Diagonal-oriented asterisks represent significance for the circadian period, vertical-oriented asterisks represent significance for relative amplitude error. $(E)$ pCCA1:LUC average luminescence traces of seedlings entrained for eight days to a 12/12 h light/dark cycles on Ctr. and Def. media before released into DD, $(F)$ respective relative amplitude error. Significance was verified by Two-Sample Student's $t$-test at $95 \%$ confidence interval $\left({ }^{\star \star *} P<0.001\right)$.
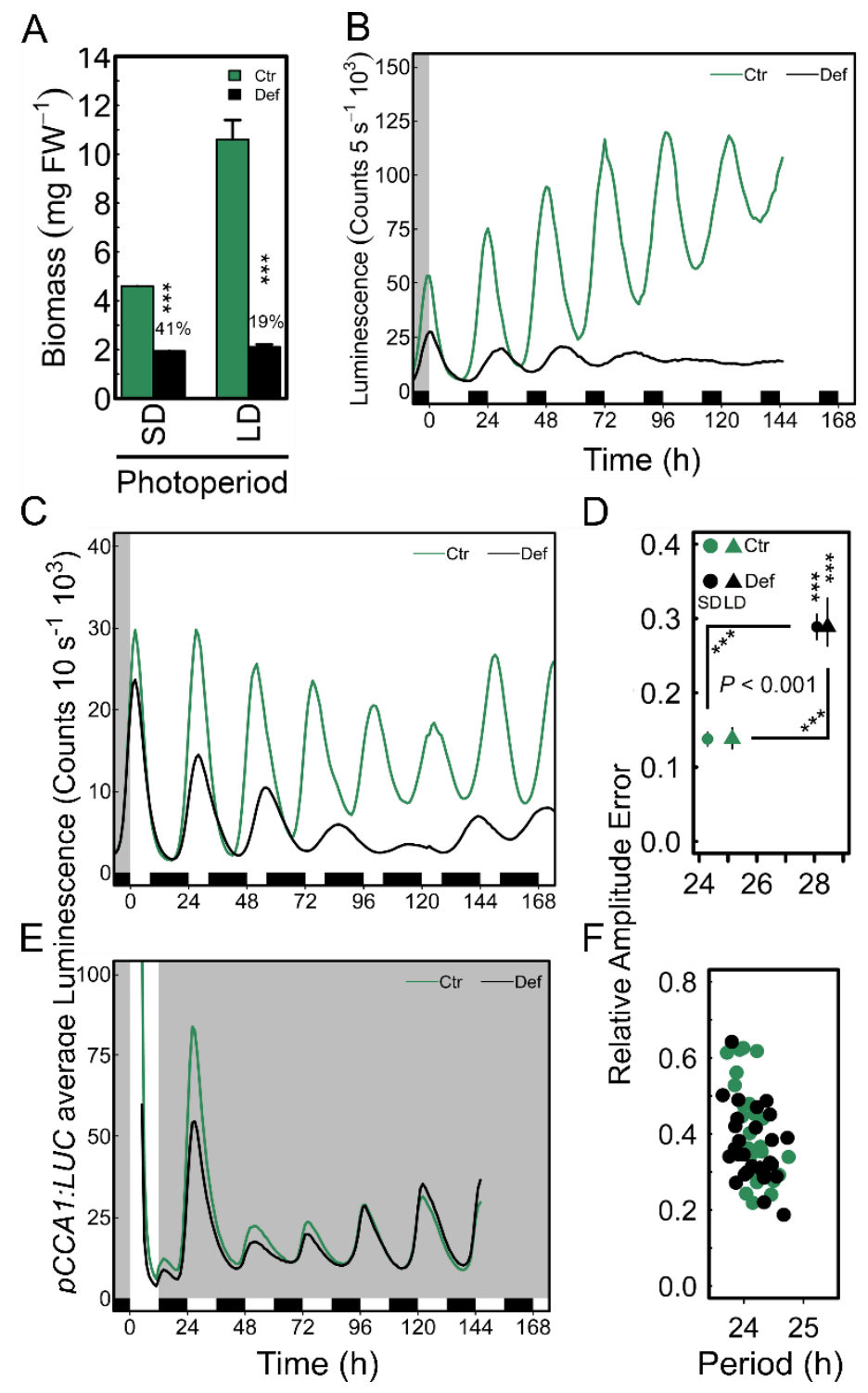
Fig. 5. An active photosynthetic system is not required to detect Mg deficiencydependent circadian alterations. Seedlings entrained for eight days to 16/8-h light/dark cycles on either $200 \mu \mathrm{M}$ (Ctr) or $5 \mu \mathrm{M}$ (Def) Mg media were released into $\mathrm{LL}$ in the presence or absence of $20 \mu \mathrm{M}$ DCMU. The experiment was independently repeated [Experiment $1 \mathrm{~A}$ $\mathrm{C}$; Experiment $2 \mathrm{D}-\mathrm{F}] .(A, D)$ Luminescence traces of $p C C A 1: L U C+$ reporter in $\mathrm{LL},(B, E)$ estimated circadian period (h) of $p C C A 1$ :LUC activity (mean \pm SEM, $n=12),(C, F)$ relative amplitude error of $p C C A 1:$ LUC oscillations (mean \pm SEM, $n=12$ ). Statistical significance was verified by factorial ANOVA followed by Tukey HSD post-hoc (different letters indicate significance at the level of $P<0.05)$. Experiments were undertaken in the laboratories at Université libre de Bruxelles $(A-C)$ and Cambridge University $(D-F)$.

A

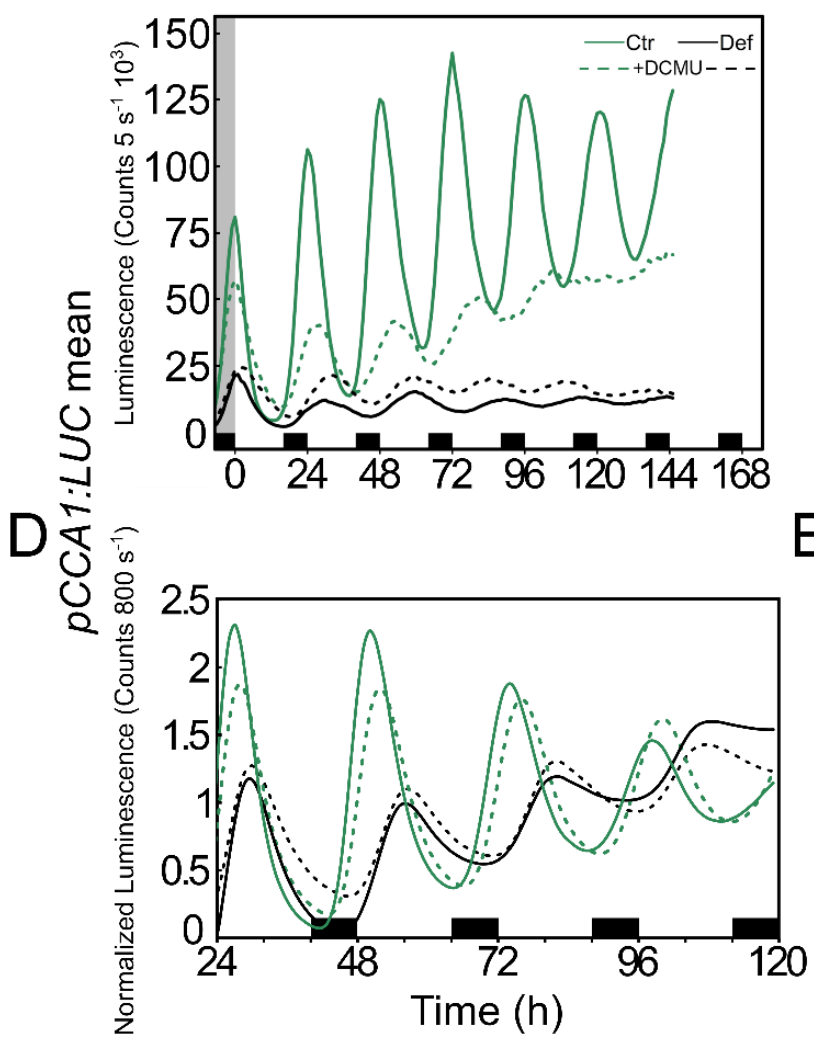

B

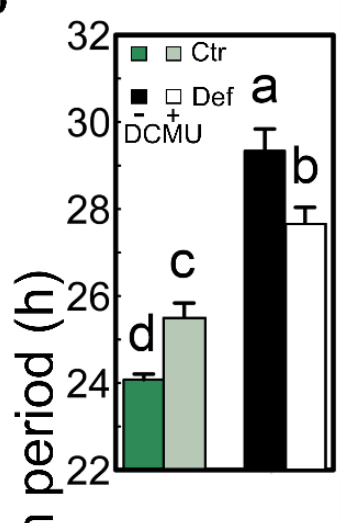

C

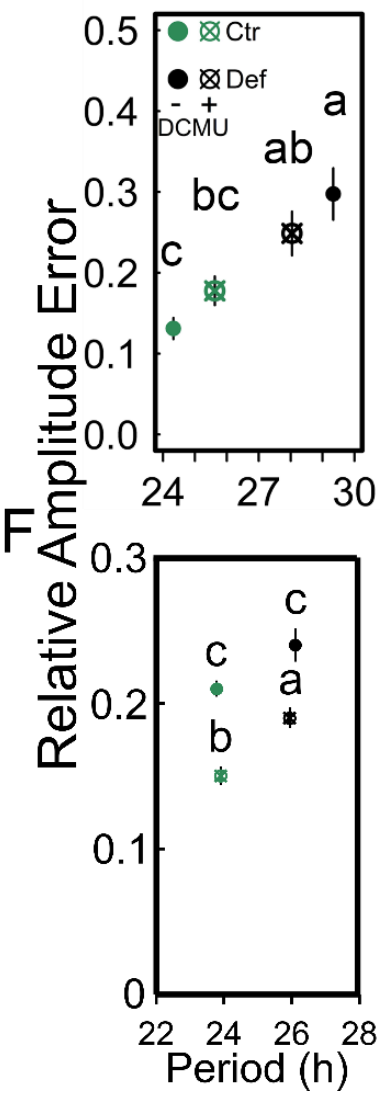


bioRxiv preprint doi: https://doi.org/10.1101/2020.05.14.096537; this version posted May 19, 2020. The copyright holder for this preprint (which was not certified by peer review) is the author/funder. All rights reserved. No reuse allowed without permission.

Fig. 6. $\mathrm{Mg}$ is not a zeitgeber to set circadian time. Seedlings were entrained for eight days to 12/12-h light/dark cycles on medium supplied with $50 \mu \mathrm{M} \mathrm{Mg}$ before released into LL. A pulse of $10 \mathrm{mM} \mathrm{Mg}$ was applied during $4 \mathrm{~h}$ in $3 \mathrm{~h}$ intervals from ZTO in LL along one circadian cycle. $(A)$ Phase response of $p C C A 1: L U C$ activity rhythms to pulses of $\mathrm{Mg}$ at different time points in LL. (B) RAE of the oscillations (mean $\pm \mathrm{SEM}, n=6$ ). (C) RAE of pCCA1:LUC oscillations of seedlings entrained on medium containing $5 \mu \mathrm{M} \mathrm{Mg}$ that were resupplied with $3 \mathrm{mM}$ Mg every 3 hours under LL conditions (means $\pm \mathrm{SEM}, \mathrm{n}=6$ ).
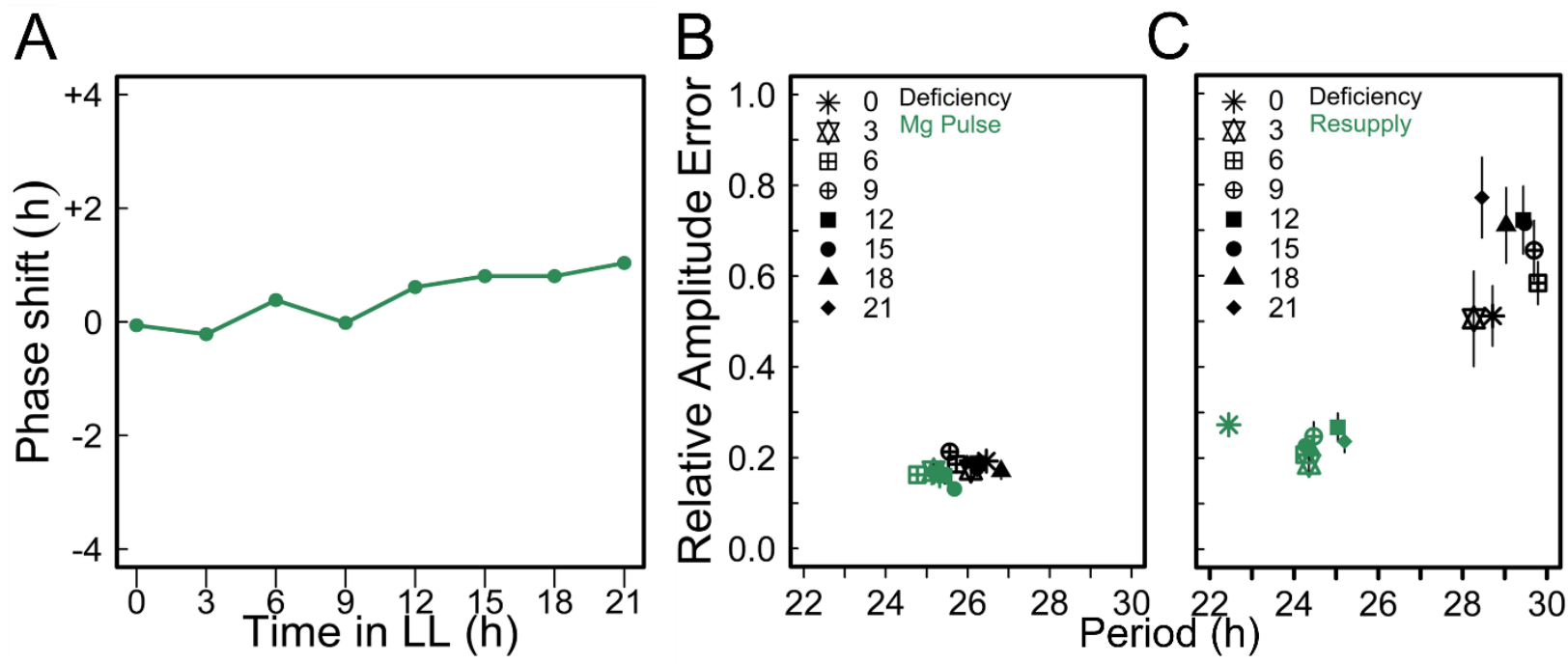
bioRxiv preprint doi: https://doi.org/10.1101/2020.05.14.096537; this version posted May 19, 2020. The copyright holder for this preprint (which was not certified by peer review) is the author/funder. All rights reserved. No reuse allowed without permission.

Fig. 7. Simulation of global effect of $\mathrm{Mg}$ deficiency on transcription/translation rate increases the circadian period of CCA1 activity rhythms. $(A)$ CCA1/LHY oscillations under Mg deficiency (blue) and when Mg was resupplied (red) under the assumption that $\mathrm{Mg}$ deficiency affects global rates of transcription and translation. Vertical red bar represents the time of simulated Mg resupply. (B) response curve to Mg pulse.

A

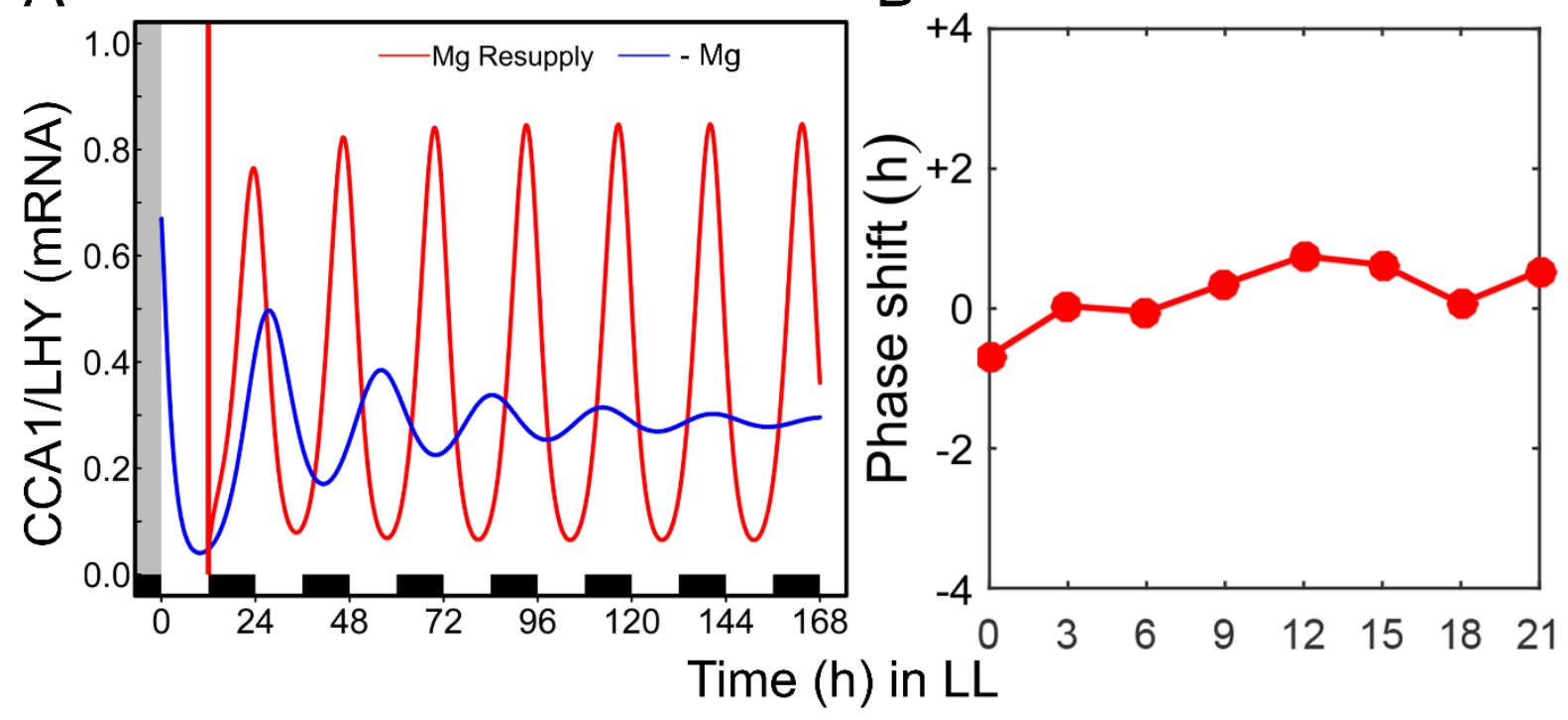


bioRxiv preprint doi: https://doi.org/10.1101/2020.05.14.096537; this version posted May 19, 2020. The copyright holder for this preprint (which was not certified by peer review) is the author/funder. All rights reserved. No reuse allowed without permission.

Fig. 8. Inhibiting translation increases circadian period of pCCA1:LUC. pCCA1:LUC

Col-0 seedlings were entrained for 11 days to 12 hour light/dark cycle on media supplied with different $\mathrm{Mg}$ concentrations before released into LL. Media were either without sucrose $(A-B)$ or supplemented with $1 \%$ sucrose $(C-D) .0 .5 \mu \mathrm{g} \mathrm{mL}{ }^{-1} \mathrm{CHX}(+\mathrm{CHX})$ or $0.1 \% \mathrm{DMSO}$ as control (Ctr) were applied after 24 hours in LL. Estimated circadian period in hours (h) $(A$, $C)$ and respective $\operatorname{RAE}(B, D)$ of $p C C A 1: L U C$ activity under LL after treatment. Significance was determined by a Wilcoxon Rang Sum test. Different letters indicate significance at the level of $P \leq 0.05$.

A

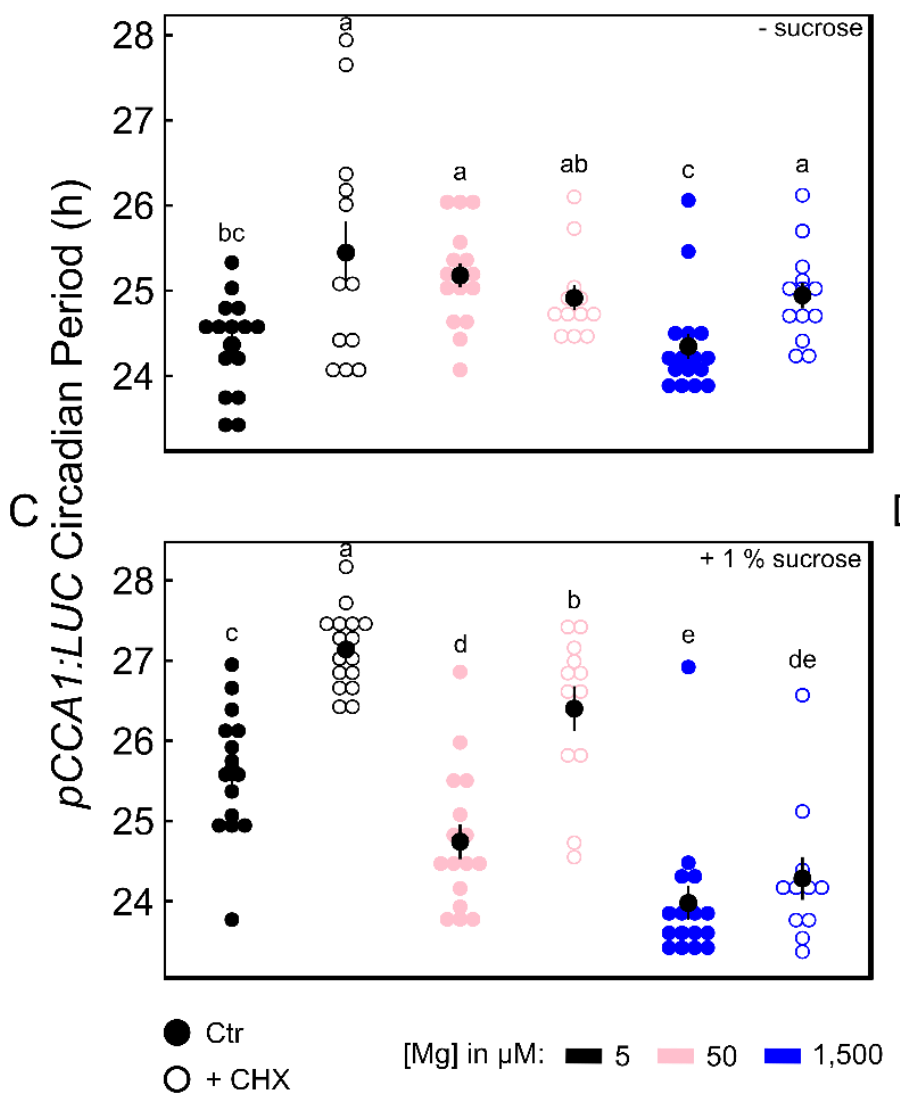

B

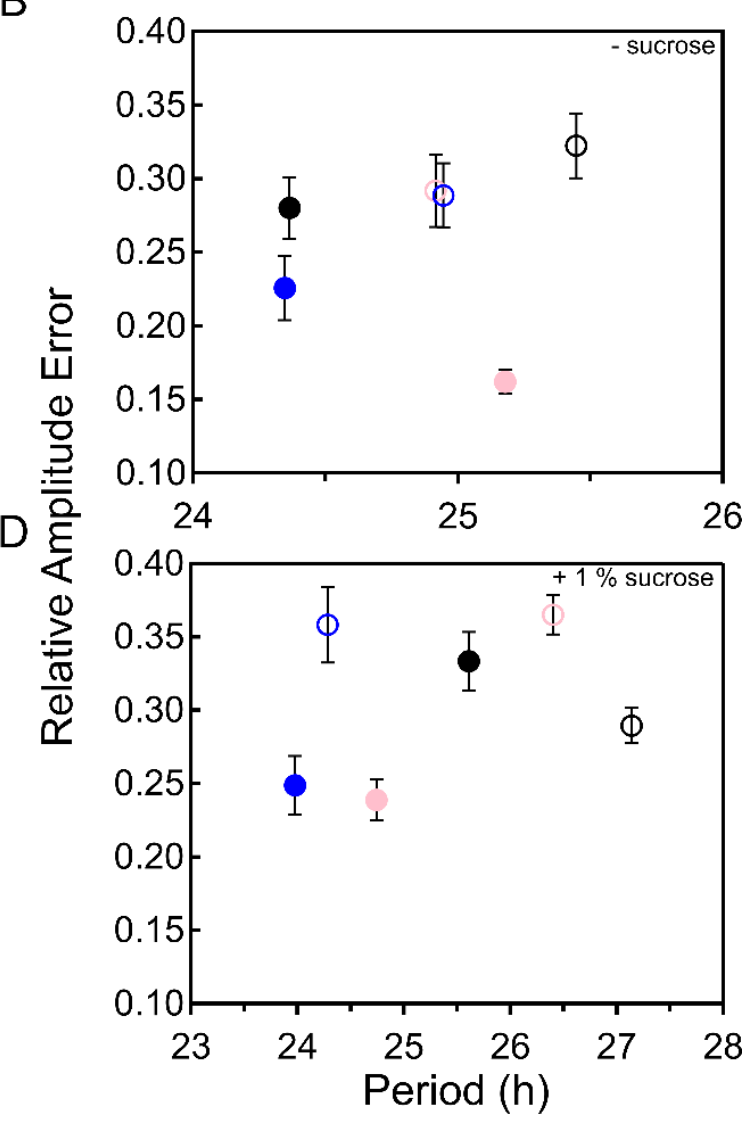




\section{Parsed Citations}

Akanuma G, Yamazaki K, Yagishi Y, lizuka Y, Ishizuka M, Kawamura F, Kato-Yamada Y (2018) Magnesium suppresses defects in the formation of $70 \mathrm{~S}$ ribosomes as well as in sporulation caused by lack of several individual ribosomal proteins. $\mathrm{J}$ Bacteriol. $200: 18$

Pubmed: Author and Title

Google Scholar: Author Only Title Only Author and Title

Alabadí D, Yanovsky MJ, Más P, Harmer SL, Kay SA(2002) Critical role for CCA1 and LHY in maintaining circadian rhythmicity in Arabidopsis. Curr Biol 12: 757-761

Pubmed: Author and Title

Google Scholar: Author Only Title Only Author and Title

Andrés-Colás N, Perea-García A, Puig S, Peñarrubia L (2010) Deregulated copper transport affects Arabidopsis development especially in the absence of environmental cycles. Plant Physiol 153: 170-184

Pubmed: Author and Title

Google Scholar: Author Only Title Only Author and Title

Becher M, Talke IN, Krall L, Krämer U (2004) Cross-species microarray transcript profiling reveals high constitutive expression of metal homeostasis genes in shoots of the zinc hyperaccumulator Arabidopsis halleri. Plant J 37: 251-268

Pubmed: Author and Title

Google Scholar: Author Only Title Only Author and Title

Cakmak I, Hengeler C, Marschner H (1994) Changes in phloem export of sucrose in leaves in response to phosphorus, potassium and magnesium deficiency in bean plants. 45 (9): 1251-1257

Pubmed: Author and Title

Google Scholar: Author Only Title Only Author and Title

De Caluwé J, de Melo JRF, Tosenberger A, Hermans C, Verbruggen N, Leloup JC, Gonze D (2017) Modeling the photoperiodic entrainment of the plant circadian clock. J Theor Biol 420: 220-231

Pubmed: Author and Title

Google Scholar: Author Only Title Only Author and Title

De Caluwé J, Xiao Q, Hermans C, Verbruggen N, Leloup JC, Gonze D (2016) A compact model for the complex plant circadian clock. Front Plant Sci 7: 74

Pubmed: Author and Title

Google Scholar: Author Only Title Only Author and Title

Chen Y-Y, Wang Y, Shin L-J, Wu J-F, Shanmugam V, Tsednee M, Lo J-C, Chen C-C, Wu S-H, Yeh K-C (2013) Iron is involved in the maintenance of circadian period length in Arabidopsis. Plant Physiol 161: 1409-1420

Pubmed: Author and Title

Google Scholar: Author Only Title Only Author and Title

Chen ZC, Peng WT, Li J, Liao H (2017) Functional dissection and transport mechanism of magnesium in plants. Semin Cell Dev Biol 74: 142-152

Pubmed: Author and Title

Google Scholar: Author Only Title Only Author and Title

Clark FW, Washington HS (1924) The Composition of the Earth's Crust. U.S. overnment Printing Office, Washington

Pubmed: Author and Title

Google Scholar: Author Only Title Only Author and Title

Cowan JA(1998) Metal activation of enzymes in nucleic acid biochemistry. Chem Rev 98: 1067-1087

Pubmed: Author and Title

Google Scholar: Author Only Title Only Author and Title

Culkin F, Cox RA(1966) Sodium, potassium, magnesium, calcium and strontium in sea water. Deep Res 13: 789-804

Pubmed: Author and Title

Google Scholar: Author Only Title Only Author and Title

Dalchau N, Baek SJ, Briggs HM, Robertson FC, Dodd AN, Gardner MJ, Stancombe MA, Haydon MJ, Stan GB, Gonçalves JM, et al (2011) The circadian oscillator gene GIGANTEA mediates a long-term response of the Arabidopsis thaliana circadian clock to sucrose. Proc Natl Acad Sci U S A 108: 5104-5109

Pubmed: Author and Title

Google Scholar: Author Only Title Only Author and Title

Ding Y, Luo W, Xu G (2006) Characterisation of magnesium nutrition and interaction of magnesium and potassium in rice. Ann Appl Biol 149:111-123

Pubmed: Author and Title

Google Scholar: Author Only Title Only Author and Title

Dodd AN, Salathia N, Hall A, Kévei E, Tóth R, Nagy F, Hibberd JM, Millar AJ, Webb AA(2005) Plant Circadian Clocks Increase

Photosynthesis, Growth, Survival, and Competitive Advantage. Science 309: 630-633

Pubmed: Author and Title

Google Scholar: Author Only Title Only Author and Title 
Dunlap JC (1999) Molecular bases for circadian clocks. Cell 96: 271-290

Pubmed: Author and Title

Google Scholar: Author Only Title Only Author and Title

Farré EM, Harmer SL, Harmon FG, Yanovsky MJ, Kay SA(2005) Overlapping and distinct roles of PRR7 and PRR9 in the Arabidopsis circadian clock. Curr Biol 15: 47-54

Pubmed: Author and Title

Google Scholar: Author Only Title Only Author and Title

Feeney KA, Hansen LL, Putker M, Olivares-Yañez C, Day J, Eades LJ, Larrondo LF, Hoyle NP, O'Neill JS, van Ooijen G (2016) Daily magnesium fluxes regulate cellular timekeeping and energy balance. Nature 532: 375-379

Pubmed: Author and Title

Google Scholar: Author Only Title Only Author and Title

Fish LE, Deshaies R, Jagendorf AT, Section PB (1983) AMg2+ requirement for rapid ATP-driven protein synthesis by intact pea chloroplasts. Plant Sci Lett 31: 139-146

Pubmed: Author and Title

Google Scholar: Author Only Title Only Author and Title

Fleischer M (1954) The abundance and distribution of the chemical elements in the Earth's crust. J Chem Educ 31: $446-455$

Pubmed: Author and Title

Google Scholar: Author Only Title Only Author and Title

Flis A, Sulpice R, Seaton DD, Ivakov AA, Liput M, Abel C, Millar AJ, Stitt M (2016) Photoperiod-dependent changes in the phase of core clock transcripts and global transcriptional outputs at dawn and dusk in Arabidopsis. Plant Cell Environ 39: 1955-1981

Pubmed: Author and Title

Google Scholar: Author Only Title Only Author and Title

Frank A, Matiolli CC, Viana AJC, Hearn TJ, Kusakina J, Belbin FE, Wells Newman D, Yochikawa A, Cano-Ramirez DL, Chembath A, et al (2018) Circadian entrainment in Arabidopsis by the sugar-responsive transcription factor bZP63. Curr Biol 28: 2597-2606.e6

Pubmed: Author and Title

Google Scholar: Author Only Title Only Author and Title

Green RM, Tingay S, Wang ZY, Tobin EM (2002) Circadian rhythms confer a higher level of fitness to Arabidopsis plants. Plant Physiol 129: 576-584

Pubmed: Author and Title

Google Scholar: Author Only Title Only Author and Title

Greenham K, McClung CR (2015) Integrating circadian dynamics with physiological processes in plants. Nat Rev Genet 16: $598-610$

Pubmed: Author and Title

Google Scholar: Author Only Title Only Author and Title

Grzebisz W(2009) Magnesium-food and human health. J Elem, 299-323

Pubmed: Author and Title

Google Scholar: Author Only Title Only Author and Title

Gutiérrez RA, Stokes TL, Thum K, Xu X, Obertello M, Katari MS, Tanurdzic M, Dean A, Nero DC, McClung CR, et al (2008) Systems approach identifies an organic nitrogen-responsive gene network that is regulated by the master clock control gene CCA1. PNAS 105: 4939-4944

Pubmed: Author and Title

Google Scholar: Author Only Title Only Author and Title

Harmer SL (2009) The circadian system in higher plants. Annu Rev Plant Biol 60: 357-377

Pubmed: Author and Title

Google Scholar: Author Only Title Only Author and Title

Hauer-Jákli M, Tränkner M (2019) Critical leaf magnesium thresholds and the impact of magnesium on plant growth and photooxidative defense: Asystematic review and meta-analysis from 70 years of research. Front Plant Sci 10: 766

Pubmed: Author and Title

Google Scholar: Author Only Title Only Author and Title

Haydon MJ, Mielczarek O, Robertson FC, Hubbard KE, Webb AAR (2013) Photosynthetic entrainment of the Arabidopsis thaliana circadian clock. Nature 502: 689-692

Pubmed: Author and Title

Google Scholar: Author Only Title Only Author and Title

Haydon MJ, Román Á, Arshad W (2015) Nutrient homeostasis within the plant circadian network. Front Plant Sci 6: 299 Pubmed: Author and Title

Google Scholar: Author Only Title Only Author and Title

Haydon MJ, Webb AAR (2016) Assessing the impact of photosynthetic sugars on the Arabidopsis circadian clock. Environ Responses Plants Methods Mol Biol. doi: 10.1007/978-1-4939-3356-3_12

Pubmed: Author and Title

Google Scholar: Author Only Title Only Author and Title 
Hermans C, Johnson GN, Strasser RJ, Verbruggen N (2004) Physiological characterisation of magnesium deficiency in sugar beet: acclimation to low magnesium differentially affects photosystems I and II. Planta 220:344-355

Pubmed: Author and Title

Google Scholar: Author Only Title Only Author and Title

Hermans C, Verbruggen N (2005) Physiological characteriza- tion of magnesium deficiency in Arabidopsis thaliana.J Exp Bot 56:2153-

2161

Pubmed: Author and Title

Google Scholar: Author Only Title Only Author and Title

Hermans C, Bourgis F, Faucher M, Strasser RJ, Delrot S, Verbruggen N (2005) Magnesium deficiency in sugar beets alters sugar partitioning and phloem loading in young mature leaves. Planta 220: 541-549

Pubmed: Author and Title

Google Scholar: Author Only Title Only Author and Title

Hermans C, Conn SJ, Chen J, Xiao Q, Verbruggen N (2013) An update on magnesium homeostasis mechanisms in plants. Metallomics 5: 1170

Pubmed: Author and Title

Google Scholar: Author Only Title Only Author and Title

Hermans C, Verbruggen N (2005) Physiological characterization of Mg deficiency in Arabidopsis thaliana. J Exp Bot 56: 2153-2161

Pubmed: Author and Title

Google Scholar: Author Only Title Only Author and Title

Hermans C, Vuylsteke M, Coppens F, Craciun A, Inzé D, Verbruggen N (2010a) Early transcriptomic changes induced by magnesium deficiency in Arabidopsis thaliana reveal the alteration of circadian clock gene expression in roots and the triggering of abscisic acidresponsive genes. New Phytol 187: 119-131

Pubmed: Author and Title

Google Scholar: Author Only Title Only Author and Title

Hermans C, Vuylsteke M, Coppens F, Cristescu SM, Harren FJM, Inzé D, Verbruggen N (2010b) Systems analysis of the responses to long-term magnesium deficiency and restoration in Arabidopsis thaliana. New Phytol 187: 132-144

Pubmed: Author and Title

Google Scholar: Author Only Title Only Author and Title

Hicks KA, Millar AJ, Carré IA, Somers DE, Straume M, Meeks-Wagner DR, Kay SA(1996) Conditional circadian dysfunction of the Arabidopsis early-flowering 3 mutant. Science 274: 790-792

Pubmed: Author and Title

Google Scholar: Author Only Title Only Author and Title

Hong S, Kim SA, Guerinot M Lou, Robertson McClung C (2013) Reciprocal interaction of the circadian clock with the iron homeostasis network in Arabidopsis. Plant Physiol 161: 893-903

Pubmed: Author and Title

Google Scholar: Author Only Title Only Author and Title

Hotta CT, Gardner MJ, Hubbard KE, Baek SJ, Dalchau N, Suhita D, Dodd AN, Webb AAR (2007) Modulation of environmental responses of plants by circadian clocks. Plant, Cell Environ 30: 333-349

Pubmed: Author and Title

Google Scholar: Author Only Title Only Author and Title

Hsu PY, Harmer SL (2014) Wheels within wheels: The plant circadian system. Trends Plant Sci 19: 240-249

Pubmed: Author and Title

Google Scholar: Author Only Title Only Author and Title

Johnson CH (1992) Phase Response Curves: what do they tell use about circadian clocks?, Circadian. Hokkaido University Press,

Sappora

Pubmed: Author and Title

Google Scholar: Author Only Title Only Author and Title

Kamiya T, Yamagami M, Hirai MY, Fujiwara T (2012) Establishment of an in planta magnesium monitoring system using CAX3 promoterluciferase in Arabidopsis. J Exp Bot 63: 355-363

Pubmed: Author and Title

Google Scholar: Author Only Title Only Author and Title

Klein DJ, Moore PB, Steitz TA(2004) The contribution of metal ions to the structural stability of the large ribosomal subunit. RNA 10:

1366-79

Pubmed: Author and Title

Google Scholar: Author Only Title Only Author and Title

Levitt LS (1954) The role of magnesium in photosynthesis. Science 120: 33-35

Pubmed: Author and Title

Google Scholar: Author Only Title Only Author and Title

Lilley RM, Holborow K, Walker DA (1974) Magnesium activation of photosynthetic CO2-fixation in a reconstituted chloroplast system. 
New Phytol 73: 657-662

Pubmed: Author and Title

Google Scholar: Author Only Title Only Author and Title

McClung CR (2006) Plant circadian rhythms. Plant Cell 18: 792-803

Pubmed: Author and Title

Google Scholar: Author Only Title Only Author and Title

Missra A, Ernest B, Lohoff T, Jia Q, Satterlee J, Ke K, Von Arnim AG (2015) The circadian clock modulates global daily cycles of mRNA ribosome loading. Plant Cell 27: 2582-2599

Pubmed: Author and Title

Google Scholar: Author Only Title Only Author and Title

Mombaerts L, Carignano A, Robertson FC, Hearn TJ, Junyang J, Hayden D, Rutterford Z, Hotta CT, Hubbard KE, Maria MRC, et al (2019) Dynamical differential expression (DyDE) reveals the period control mechanisms of the Arabidopsis circadian oscillator. PLOS Comput Biol 15: e1006674

Pubmed: Author and Title

Google Scholar: Author Only Title Only Author and Title

Osuna D, Usadel B, Morcuende R, Gibon Y, Bläsing OE, Höhne M, Günter M, Kamlage B, Trethewey R, Scheible W-R, et al (2007) Temporal responses of transcripts, enzyme activities and metabolites after adding sucrose to carbon-deprived Arabidopsis seedlings. Plant J 49: 463-491

Pubmed: Author and Title

Google Scholar: Author Only Title Only Author and Title

Philippou K, Ronald J, Sánchez-Villarreal A, Davis AM, Davis SJ (2019) Physiological and genetic dissection of sucrose inputs to the Arabidopsis thaliana circadian system Genes 10: 334

Pubmed: Author and Title

Google Scholar: Author Only Title Only Author and Title

Robertson FC, Skeffington AW, Gardner MJ, Webb AAR (2009) Interactions between circadian and hormonal signalling in plants. Plant Mol Biol 69: 419-427

Pubmed: Author and Title

Google Scholar: Author Only Title Only Author and Title

Römheld V (2012) Diagnosis of deficiency and toxicity of nutrients. In: Marschner P (ed) Mineral nutrition of higher plants; 3rd edn.

Elsevier Ltd., pp 299-311

Pubmed: Author and Title

Google Scholar: Author Only Title Only Author and Title

Salomé PA, McClung CR (2005) Pseudo-response Regulator 7 and 9 are partially redundant genes essential for the temperature responsiveness of the Arabidopsis circadian clock. Plant Cell 17: 791-803

Pubmed: Author and Title

Google Scholar: Author Only Title Only Author and Title

Salomé PA, Oliva M, Weigel D, Krämer U (2013) Circadian clock adjustment to plant iron status depends on chloroplast and phytochrome function. EMBO J 32: 511-523

Pubmed: Author and Title

Google Scholar: Author Only Title Only Author and Title

Seaton DD, Graf A, Baerenfaller K, Stitt M, Millar AJ, Gruissem W (2018) Photoperiodic control of the Arabidopsis proteome reveals a translational coincidence mechanism Mol Syst Biol. 14 (3). doi: 10.15252/msb.20177962

Pubmed: Author and Title

Google Scholar: Author Only Title Only Author and Title

Shor E, Paik I, Kangisser S, Green R, Huq E (2017) PHYTOCHROME INTERACTING FACTORS mediate metabolic control of the circadian system in Arabidopsis. New Phytol 215: 217-228

Pubmed: Author and Title

Google Scholar: Author Only Title Only Author and Title

Sperrazza JM, Spremulli LL (1983) Quantitation of cation binding to wheat germ ribosomes: Influences on submit association equilibria and ribosome activity. Nucleic Acids Res 11: 2665-2679

Pubmed: Author and Title

Google Scholar: Author Only Title Only Author and Title

Strasser RJ, Butler WL (1977) Energy transfer and the distribution of excitation energy in the photosynthetic apparatus of spinach chloroplasts. BBA- Bioenerg 460: 230-238

Pubmed: Author and Title

Google Scholar: Author Only Title Only Author and Title

Sweeney BM, Folli SI (1984) Nitrate deficiency shortens the circadian period in Gonyaulax. Plant Physiol 75: 242-245

Pubmed: Author and Title

Google Scholar: Author Only Title Only Author and Title

Takahashi N, Hirata Y, Aihara K, Mas P (2015) A hierarchical multi-oscillator network orchestrates the Arabidopsis circadian system 
Cell 163: 148-159

Pubmed: Author and Title

Google Scholar: Author Only Title Only Author and Title

Verbruggen N, Hermans C (2013) Physiological and molecular responses to magnesium nutritional imbalance in plants. Plant Soil 368: 87-99

Pubmed: Author and Title

Google Scholar: Author Only Title Only Author and Title

Walker CJ, Weinstein JD (1991) Further characterization of the magnesium chelatase in isolated developing cucumber chloroplasts.

Plant Physiol 95: 1189-1196

Pubmed: Author and Title

Google Scholar: Author Only Title Only Author and Title

Wang QM, Guan KL, Roach PJ, DePaoli-Roach AA(1995) Phosphorylation and activation of the ATP-Mg-dependent protein phosphatase by the mitogen-activated protein kinase. J Biol Chem 270: 18352-18358

Pubmed: Author and Title

Google Scholar: Author Only Title Only Author and Title

Webb AAR (2003) The physiology of circadian rhythms in plants. New Phytol 160: 281-303

Pubmed: Author and Title

Google Scholar: Author Only Title Only Author and Title

Webb AAR, Seki M, Satake A, Caldana C (2019) Continuous dynamic adjustment of the plant circadian oscillator. Nat Commun 10: 550 Pubmed: Author and Title

Google Scholar: Author Only Title Only Author and Title

Weiss RL, Morris DR (1973) Cations and ribosome structure. I. Effects of the 30S subunit of substituting polyamines for magnesium ion. Biochemistry 12: 435-441

Pubmed: Author and Title

Google Scholar: Author Only Title Only Author and Title

Zielinski T, Moore AM, Troup E, Halliday KJ, Millar AJ (2014) Strengths and limitations of period estimation methods for circadian data. PLoS One 9: e96462

Pubmed: Author and Title

Google Scholar: Author Only Title Only Author and Title 